\title{
The relationship between milk metabolome and methane emission of Holstein Friesian dairy cows: Metabolic interpretation and prediction potential
}

\author{
S. van Gastelen, ${ }^{*} \dagger^{1}$ E. C. Antunes-Fernandes, ${ }^{*} \ddagger$ K. A. Hettinga, $\ddagger$ and J. Dijkstra† \\ ${ }^{*}$ Top Institute Food and Nutrition, PO Box 557, 6700 AN Wageningen, the Netherlands \\ †Animal Nutrition Group, Wageningen University \& Research, PO Box 338, 6700 AH Wageningen, the Netherlands \\ fFood Quality and Design Group, Wageningen University \& Research, PO Box 17, $6700 \mathrm{AH}$ Wageningen, the Netherlands
}

\begin{abstract}
This study aimed to quantify the relationship between $\mathrm{CH}_{4}$ emission and fatty acids, volatile metabolites, and nonvolatile metabolites in milk of dairy cows fed foragebased diets. Data from 6 studies were used, including 27 dietary treatments and 123 individual observations from lactating Holstein-Friesian cows. These dietary treatments covered a large range of forage-based diets, with different qualities and proportions of grass silage and corn silage. Methane emission was measured in climate respiration chambers and expressed as production (g per day), yield (g per kg of dry matter intake; DMI), and intensity (g per $\mathrm{kg}$ of fat- and protein-corrected milk; FPCM). Milk samples were analyzed for fatty acids by gas chromatography, for volatile metabolites by gas chromatography-mass spectrometry, and for nonvolatile metabolites by nuclear magnetic resonance. Dry matter intake was $15.9 \pm 1.90 \mathrm{~kg} / \mathrm{d}($ mean $\pm \mathrm{SD})$, FPCM yield was $25.2 \pm 4.57 \mathrm{~kg} / \mathrm{d}, \mathrm{CH}_{4}$ production was $359 \pm 51.1 \mathrm{~g} / \mathrm{d}, \mathrm{CH}_{4}$ yield was $22.6 \pm 2.31 \mathrm{~g} / \mathrm{kg}$ of DMI, and $\mathrm{CH}_{4}$ intensity was $14.5 \pm 2.59 \mathrm{~g} / \mathrm{kg}$ of FPCM. The results show that changes in individual milk metabolite concentrations can be related to the ruminal $\mathrm{CH}_{4}$ production pathways. Several of these relationships were diet driven, whereas some were partly dependent on FPCM yield. Next, prediction models were developed and subsequently evaluated based on root mean square error of prediction (RMSEP), concordance correlation coefficient (CCC) analysis, and random 10-fold crossvalidation. The best models with milk fatty acids (in $\mathrm{g} / 100 \mathrm{~g}$ of fatty acids; MFA) alone predicted $\mathrm{CH}_{4}$ production, yield, and intensity with a RMSEP of $34 \mathrm{~g} / \mathrm{d}$, $2.0 \mathrm{~g} / \mathrm{kg}$ of DMI, and $1.7 \mathrm{~g} / \mathrm{kg}$ of FPCM, and with a CCC of $0.67,0.44$, and 0.75 , respectively. The $\mathrm{CH}_{4}$ prediction potential of both volatile metabolites alone and nonvolatile metabolites alone was low, regardless of the unit of $\mathrm{CH}_{4}$ emission, as evidenced by the low
\end{abstract}

Received June 14, 2017.

Accepted November 9, 2017.

${ }^{1}$ Corresponding author: sanne.vangastelen@wur.nl
CCC values $(<0.35)$. The best models combining the 3 types of metabolites as selection variables resulted in the inclusion of only MFA for $\mathrm{CH}_{4}$ production and $\mathrm{CH}_{4}$ yield. For $\mathrm{CH}_{4}$ intensity, MFA, volatile metabolites, and nonvolatile metabolites were included in the prediction model. This resulted in a small improvement in prediction potential (CCC of 0.80 ; RMSEP of $1.5 \mathrm{~g} / \mathrm{kg}$ of FPCM) relative to MFA alone. These results indicate that volatile and nonvolatile metabolites in milk contain some information to increase our understanding of enteric $\mathrm{CH}_{4}$ production of dairy cows, but that it is not worthwhile to determine the volatile and nonvolatile metabolites in milk to estimate $\mathrm{CH}_{4}$ emission of dairy cows. We conclude that MFA have moderate potential to predict $\mathrm{CH}_{4}$ emission of dairy cattle fed forage-based diets, and that the models can aid in the effort to understand and mitigate $\mathrm{CH}_{4}$ emissions of dairy cows.

Key words: dairy cow, enteric methane production, milk metabolome

\section{INTRODUCTION}

Enteric $\mathrm{CH}_{4}$ production is one of the main targets of greenhouse gas mitigation practices for the dairy industry (Hristov et al., 2013). Quantification of enteric $\mathrm{CH}_{4}$ production is therefore important. Several $\mathrm{CH}_{4}$ measuring techniques have been developed, but these are not yet suitable for large scale measurements (Hammond et al., 2016). Proxies (i.e., indirect traits or indicators correlated with $\mathrm{CH}_{4}$ emission) might, therefore, serve as a good alternative.

Milk fatty acid (MFA) concentrations have been suggested as proxy to estimate $\mathrm{CH}_{4}$ emission in dairy cattle, and many studies have evaluated this proposed relationship between MFA concentrations and $\mathrm{CH}_{4}$ emission (Chilliard et al., 2009; Mohammed et al., 2011; Rico et al., 2016). However, the results of these studies are inconsistent, with some studies finding a clear and strong relationship between MFA and $\mathrm{CH}_{4}$ emission (Chilliard et al., 2009; Rico et al., 2016), whereas other studies conclude that MFA alone might not be suitable to develop universal $\mathrm{CH}_{4}$ prediction models 
(Mohammed et al., 2011). Recently, Castro-Montoya et al. (2017) concluded that MFA are not reliable predictors for specific amounts of $\mathrm{CH}_{4}$ emitted by a cow. Furthermore, individual MFA selected in optimal models to predict $\mathrm{CH}_{4}$ emission largely differ between studies, further hampering the applicability of MFA to predict $\mathrm{CH}_{4}$ emission in various circumstances. Some of these inconsistencies can be explained by dietary composition and lactation stage, both being factors that can influence the relationship between MFA and $\mathrm{CH}_{4}$ emission (Mohammed et al., 2011; Dijkstra et al., 2016; Vanrobays et al., 2016).

These findings warrant further investigation of other proxies in milk to estimate $\mathrm{CH}_{4}$ emission of dairy cattle, including volatile metabolites and nonvolatile metabolites. Antunes-Fernandes et al. (2016) and van Gastelen et al. (2017) evaluated the relationship between $\mathrm{CH}_{4}$ emission and both volatile and nonvolatile metabolites in milk to better understand the biological pathways involved in $\mathrm{CH}_{4}$ emission in dairy cattle as well as to determine the prediction potential of these milk metabolites. Antunes-Fernandes et al. (2016) concluded that $\mathrm{CH}_{4}$ intensity $(\mathrm{g} / \mathrm{kg}$ of fat- and protein-corrected milk; FPCM) may be related to lactose synthesis and energy metabolism in the mammary gland, as reflected by the significant relationship between both milk nonvolatile metabolites citrate and uridine diphosphate (UDP)hexose $\mathrm{B}$ and $\mathrm{CH}_{4}$ intensity. Methane yield $(\mathrm{g} / \mathrm{kg}$ of DMI), on the other hand, may be related to glucogenic nutrient supply, as reflected by the milk nonvolatile metabolite acetone. In a recent review of $\mathrm{CH}_{4}$ proxies, Negussie et al. (2017) concluded that no single proxy accurately predicts $\mathrm{CH}_{4}$ emission, and that combining 2 or more proxies is the best way forward for the prediction of $\mathrm{CH}_{4}$ emission. Van Gastelen et al. (2017) concluded that volatile metabolites and, in particular, nonvolatile metabolites in combination with MFA hold potential to predict $\mathrm{CH}_{4}$ emission of dairy cows more precisely and accurately compared with MFA alone. The improved prediction potential was relatively small (i.e., the increase in adjusted $\mathrm{R}^{2}$ and $\mathrm{CCC}$ is $<0.18$ and $<0.12$, respectively) for $\mathrm{CH}_{4}$ production $(\mathrm{g} / \mathrm{d})$ and $\mathrm{CH}_{4}$ yield $(\mathrm{g} / \mathrm{kg}$ of DMI), whereas the prediction potential for $\mathrm{CH}_{4}$ intensity $(\mathrm{g} / \mathrm{kg}$ of $\mathrm{FPCM}$ ) increased considerably (i.e., the adjusted $\mathrm{R}^{2}$ and $\mathrm{CCC}$ increased with 0.36 and 0.24 , respectively).

The analysis of both Antunes-Fernandes et al. (2016) and van Gastelen et al. (2017) was based upon a small range of diets (i.e., 4 forage-based diets in which grass silage was replaced partly or fully by corn silage) in one experiment. Therefore, the present study aims to quantify the relationship between $\mathrm{CH}_{4}$ emission and the milk metabolome in dairy cattle fed a range of forage- based diets with different qualities and proportions of grass silage and corn silage.

\section{MATERIALS AND METHODS}

\section{Experiments and Data}

Data on individual cows from 6 experiments, all designed as randomized block experiments, from Wageningen University \& Research (Wageningen, the Netherlands) were used. These experiments were conducted in accordance with Dutch law, and approved by the Animal Care and Use Committee of Wageningen University \& Research. Experiment 1 (Warner et al., 2015) involved 25 Holstein-Friesian dairy cows and 4 grass herbage diets (forage to concentrate ratio of 85:15 based on DM basis). The grass herbage was cut after 3 or 5 wk of regrowth, after receiving either a low $(20 \mathrm{~kg}$ of $\mathrm{N} / \mathrm{ha}$ ) or a high (90 kg of N/ha) fertilization rate after initial cut. Experiment 2 (van Gastelen et al., 2015) involved 29 Holstein-Friesian dairy cows and 4 diets (forage to concentrate ratio of 80:20 on DM basis). The forage consisted of $1,000 \mathrm{~g} / \mathrm{kg}$ of DM grass silage, 1,000 $\mathrm{g} / \mathrm{kg}$ of DM corn silage, or a mixture of both silages $(667 \mathrm{~g} / \mathrm{kg}$ of DM grass silage and $333 \mathrm{~g} / \mathrm{kg}$ of DM corn silage; $333 \mathrm{~g} / \mathrm{kg}$ of DM grass silage and $667 \mathrm{~g} / \mathrm{kg}$ of DM corn silage). Experiment 3 (Warner et al., 2016) involved 52 Holstein-Friesian dairy cows and 6 grass silage-based diets (forage to concentrate ratio of 80:20 on DM basis). The grass silage received low (65 kg of $\mathrm{N} /$ ha) or high (150 kg of $\mathrm{N} / \mathrm{ha}$ ) $\mathrm{N}$ fertilization level preceding its growth period, and there were 3 regrowth periods $(28,41$, and $62 \mathrm{~d}$ of regrowth). Experiment 4 (Warner et al., 2017) involved 55 Holstein-Friesian dairy cows and 8 grass silage-based diets (grass silage, corn silage, and concentrate at a ratio of 70:10:20 on a DM basis). The grass silage was cut at 4 growth stages (leafy, boot, early heading, and late heading) and fed at 2 levels of DMI (15.5 and $16.6 \mathrm{~kg}$ of DM/d). Experiment 5 (Hatew et al., 2016) involved 25 HolsteinFriesian dairy cows and 4 corn silage-based diets with whole-plant corn harvested at a very early $(25 \% \mathrm{DM})$, early $(28 \% \mathrm{DM})$, medium $(32 \% \mathrm{DM})$, and late $(40 \%$ DM) stage of maturity, and with corn silage, concentrate, and wheat straw at a ratio of 75:20:5 (DM basis). Experiment 6 (Klop et al., 2017) involved 8 HolsteinFriesian dairy cows and 3 diets containing corn silage, grass silage, and concentrate at a ratio of 40:30:30 (DM basis). The concentrate was either a basal concentrate or contained a blend of essential oils or lauric acid. Repeated measures resulted in 32 observations.

The experimental setup of these experiments was similar. After an adaptation period of $12 \mathrm{~d}$, cows were 
housed individually in open circuit, indirect climate respiration chambers for a 5-d period to determine $\mathrm{CH}_{4}$ emission (expressed as production in $\mathrm{g} / \mathrm{d}$, as yield in $\mathrm{g} /$ $\mathrm{kg}$ of DMI, and as intensity in $\mathrm{g} / \mathrm{kg}$ of FPCM). The climate respiration chambers are described by Heetkamp et al. (2015) and van Gastelen et al. (2015). Cows were milked twice daily and water was freely available, both during the adaptation period and in the climate respiration chambers. Diets were fed as a TMR twice daily and intake was restricted to $95 \%$ of the voluntary DMI of the cow consuming the least within a block.

\section{Sample Collection and Analyses}

Milk yield was recorded and 10-mL milk samples were collected at each milking in the climate respiration chambers. These milk samples were analyzed for fat, protein, and lactose content, and for milk urea $\mathrm{N}$ as described by the respective studies. In addition, a representative milk sample (i.e., $5 \mathrm{~g} / \mathrm{kg}$ of milk production at each milking from each cow) was collected according to Antunes-Fernandes et al. (2016). We selected all observations from experiment $2(\mathrm{n}=29)$, and we randomly selected another 94 observations from the other experiments based on complete blocks (i.e., all cows within the same block were selected; incomplete blocks, due to observations being removed from the experiment or statistical analysis, were excluded from the selection). The selected observations, a total of 123 observations, represented all dietary treatments without feed additives (i.e., 27 in total), and resulted in no repeated measurements from the same cows. The representative milk samples matching the selected observations were subsequently analyzed for MFA composition ( $\mathrm{g} / 100 \mathrm{~g}$ of total fatty acids) using GC according to van Gastelen et al. (2015), for volatile metabolites (peak area in arbitrary units) using GC-MS according to AntunesFernandes et al. (2016), and for nonvolatile metabolites (relative area in arbitrary units) using proton nuclear magnetic resonance according to Antunes-Fernandes et al. (2016).

\section{Statistical Analyses}

Linear Regression. The descriptive statistics of the feed intake, dietary composition, animal performance, and $\mathrm{CH}_{4}$ emission are presented in Table 1. Descriptive statistics of the MFA, volatile metabolites, and nonvolatile metabolites used for modeling are presented in Supplemental Table S1 (https://doi.org/10.3168/jds .2017-13334). To determine the relationship between $\mathrm{CH}_{4}$ emission (i.e., production, yield, and intensity) and individual MFA, volatile metabolites, and nonvolatile metabolites, mixed model univariate regression procedures (PROC MIXED of SAS; version 9.2, SAS Institute Inc., Cary, NC) were applied. These included a random experiment effect and individual MFA, volatile metabolites, and nonvolatile metabolites as fixed effects. Having the experiment effect as a random effect resulted in the equation parameter estimates to be estimated first within study, and then averaged to obtain overall estimates. To evaluate the influence of FPCM on the established relationships between individual MFA, volatile metabolites or nonvolatile metabolites and $\mathrm{CH}_{4}$ intensity, FPCM was included as a covariate in the linear regressions.

Model Development. The PROC GLMSELECT procedure of SAS was used to develop multivariate models retaining the experiment effect in every step, with $\mathrm{CH}_{4}$ emission (i.e., production, yield, and intensity) as the dependent variable, the milk metabolites (i.e., MFA, volatile metabolites, and nonvolatile metabolites) as independent variables, and stepwise selection as the selection procedure. The significance level for milk metabolites to enter or stay in the model was 0.01 and 0.05 , respectively. The best models were selected based on the minimum Akaike's information criterion statistic. Adjusted independent variable values were calculated based on regression parameters of the final model to determine the adjusted $\mathrm{R}^{2}$ corrected for experiment effect, as described by St-Pierre (2001). The selected models were evaluated with the PROC REG procedure in terms of multicollinearity (variation inflation factor $>10$ ), but no multicollinearity was observed for any of the $\mathrm{CH}_{4}$ prediction models.

Model Evaluation. The $\mathrm{CH}_{4}$ prediction models were evaluated using 2 methods. First, the mean square error of prediction (MSEP), calculated as

$$
\operatorname{MSEP}=\sum_{i=1}^{n}\left(O_{i}-P_{i}\right)^{2} / n,
$$

where $n$ is the total number of observations, $O_{i}$ is the observed value, and $P_{i}$ is the predicted value. The square root of the MSEP (RMSEP), expressed in the same unit as the observed mean or as percentage of the observed mean, gives an estimate of the overall prediction error. Second, concordance correlation coefficient analysis (CCC; Lin, 1989) was performed, where CCC is calculated as

$$
\mathrm{CCC}=r \times C_{b},
$$

where $r$ is the correlation coefficient providing a measure of precision, and $C_{b}$ is a bias correction factor providing a measure of accuracy. The $C_{b}$ variable is calculated as 


$$
C_{b}=\frac{2}{\left[v+1 / v+\mu^{2}\right]},
$$

where

$$
\begin{gathered}
v=\frac{S_{o}}{S_{p}}, \\
\mu=\frac{\bar{O}-\bar{P}}{\left(S_{o} \times S_{p}\right)^{0.5}},
\end{gathered}
$$

where $v$ provides a measure of scale shift, whereas $\mu$ provides a measure of location shift, $S_{o}$ and $S_{p}$ are the observed and predicted standard deviations, and $\bar{O}$ and $\bar{P}$ are the observed and predicted means.

Cross-Validation. We performed a random crossvalidation with 10 splits and 10 iterations as recommended by Rodriguez et al. (2010) for all prediction models to calculate the performance parameters of the models (i.e., root mean square error of cross-validation; RMSECV, and the coefficient of determination of cross-validation; $\mathbf{R}^{\mathbf{2}} \mathbf{C V}$ ). For each iteration, a model was developed as described above using 9 splits of the data set, and the selected model was subsequently evaluated as described above on the remaining part of the data set (i.e., one split). The cross-validation performance values represent the average of the 10-fold cross-validation.

\section{RESULTS}

\section{Relationship Between Individual Milk Metabolites and $\mathrm{CH}_{4}$ Emission}

Milk Fatty Acids. In the present study, 43 MFA were identified. The relationships between each individual MFA and $\mathrm{CH}_{4}$ production, $\mathrm{CH}_{4}$ yield, and $\mathrm{CH}_{4}$ intensity are shown in Supplemental Tables S2, S3, and S4, respectively (https://doi.org/10.3168/ jds.2017-13334). Several short- and medium-straight even-chain MFA (SMCFA; $\leq 16$ carbon fatty acids), some odd- and branched-chain fatty acids (OBCFA; $\mathrm{C} 13: 0, \mathrm{C} 15: 0$, iso $\mathrm{C} 15: 0$, and iso $\mathrm{C} 17: 0)$, and $\mathrm{C} 20: 4 \mathrm{n}$ -3 were positively related to $\mathrm{CH}_{4}$ production, whereas another OBCFA (i.e., C17:0), all C18:1 and C18:2 isomers, and other long-chain fatty acids ( $>16$ carbon fatty acids) were negatively related to $\mathrm{CH}_{4}$ production. The SMCFA C16:0 was positively related to $\mathrm{CH}_{4}$ yield, similar to some OBCFA and several long-chain fatty acids, whereas the SMCFA C4:0, and all C18:1, C18:2,

\begin{tabular}{|c|c|c|c|c|c|}
\hline Item & Mean & Median & $\mathrm{SD}$ & Minimum & Maximum \\
\hline Forage content diet $(\mathrm{g} / 100 \mathrm{~g}$ of $\mathrm{DM})$ & 80 & 80 & 3.0 & 70 & 85 \\
\hline \multicolumn{6}{|c|}{ Dietary characteristic (in $\mathrm{g} / \mathrm{kg}$ of DM, unless stated otherwise) } \\
\hline Ash & 76 & 76 & 14.7 & 53 & 103 \\
\hline $\mathrm{CP}$ & 170 & 158 & 43.2 & 82 & 251 \\
\hline $\mathrm{NDF}$ & 386 & 386 & 53.4 & 242 & 501 \\
\hline Crude fat & 31 & 28 & 7.2 & 21 & 46 \\
\hline Starch & 111 & 79 & 92.6 & 5 & 326 \\
\hline Sugar & 95 & 76 & 66.4 & 21 & 265 \\
\hline Gross energy $(\mathrm{MJ} / \mathrm{kg}$ of $\mathrm{DM})$ & 18.6 & 18.7 & 0.41 & 17.6 & 19.3 \\
\hline NDF to starch ratio & 8.8 & 5.0 & 16.03 & 1.0 & 86.2 \\
\hline \multicolumn{6}{|l|}{ Lactation characteristic } \\
\hline Milk production $(\mathrm{kg} / \mathrm{d})$ & 22.6 & 22.5 & 3.87 & 14.6 & 33.7 \\
\hline DIM & 176 & 191 & 70.9 & 70 & 403 \\
\hline Parity & 2.6 & 2.0 & 1.29 & 1.0 & 7.0 \\
\hline \multicolumn{6}{|l|}{$\mathrm{CH}_{4}$ emission } \\
\hline $\mathrm{CH}_{4}$ production $(\mathrm{g} / \mathrm{d})$ & 359 & 358 & 51.1 & 234 & 469 \\
\hline $\mathrm{CH}_{4}$ yield $(\mathrm{g} / \mathrm{kg}$ of $\mathrm{DMI})$ & 22.6 & 22.9 & 2.31 & 17.2 & 28.0 \\
\hline $\mathrm{CH}_{4}$ intensity $(\mathrm{g} / \mathrm{kg}$ of $\mathrm{FPCM})$ & 14.5 & 14.6 & 2.59 & 8.5 & 24.0 \\
\hline
\end{tabular}

Table 1. Descriptive statistics of DMI, dietary composition, animal characteristics, and $\mathrm{CH}_{4}$ emissions $(\mathrm{n}=123)$ [data from van Gastelen et al. (2015), Warner et al. (2015, 2016, 2017), Hatew et al. (2016), and Klop et al. (2017)]

${ }^{1}$ Fat- and protein-corrected milk $(\mathrm{kg} / \mathrm{d})=[0.337+0.116 \times$ fat $(\mathrm{g} / 100 \mathrm{~g}$ of milk $)+0.06 \times$ protein $(\mathrm{g} / 100 \mathrm{~g}$ of milk $)] \times$ milk yield $(\mathrm{kg} / \mathrm{d})(\mathrm{CVB}$, 2012). 
and $\mathrm{C} 18: 3$ isomers were negatively related to $\mathrm{CH}_{4}$ yield. Furthermore, many SMCFA, OBCFA, and long-chain fatty acids were positively related to $\mathrm{CH}_{4}$ intensity, whereas mostly $\mathrm{C} 18: 1, \mathrm{C} 18: 2$, and $\mathrm{C} 18: 3$ isomers were negatively related to $\mathrm{CH}_{4}$ intensity. The relationships between each MFA and $\mathrm{CH}_{4}$ intensity including FPCM as a covariate are shown in Supplemental Table S4 (https://doi.org/10.3168/jds.2017-13334). Including FPCM as a covariate in the regression model resulted in several changes. Many MFA remained significantly related to $\mathrm{CH}_{4}$ intensity, whereas the relationship between $\mathrm{CH}_{4}$ intensity and 2 MFA (i.e., C4:0 and $\mathrm{C} 22: 5 \mathrm{n}$ -3) disappeared. In total, 8 relationships appeared or strengthened, including C6:0, C8:0, C17:1 cis-9, several $\mathrm{C} 18: 1$ isomers, and $\mathrm{C} 18: 2$ cis-9, trans-11, that became significantly related upon including FPCM as a covariate.

Volatile Metabolites. In the present study, a total of 14 volatile metabolites were identified, including ketones, aldehydes, organic acids, alcohols, esters, and sulfur compounds. The relationships between each individual volatile metabolite and $\mathrm{CH}_{4}$ production, $\mathrm{CH}_{4}$ yield, and $\mathrm{CH}_{4}$ intensity are shown in Supplemental Tables S5, S6, and S7, respectively (https://doi.org/10 .3168/jds.2017-13334). The volatile metabolites 1-pentanol, acetone, and hexanal were negatively related to $\mathrm{CH}_{4}$ production, whereas no positive relationship between volatile metabolites and $\mathrm{CH}_{4}$ production were observed. Ethyl butanoate and 2 free fatty acids (FFA; butanoic and hexanoic acid) were positively related, whereas hexanal was negatively related to $\mathrm{CH}_{4}$ yield. Many volatile metabolites were related to $\mathrm{CH}_{4}$ intensity, with 2-heptanone, ethyl butanoate, and all FFA being positively related to $\mathrm{CH}_{4}$ intensity, and 1-pentanol, acetone, and dimethyl sulfone being negatively related to $\mathrm{CH}_{4}$ intensity. The relationships between each volatile metabolite and $\mathrm{CH}_{4}$ intensity including FPCM as a covariate are shown in Supplemental Table S7 (https://doi.org/10.3168/jds.2017-13334). Including FPCM as a covariate in the regression model resulted in most volatile metabolites remaining to be related to $\mathrm{CH}_{4}$ intensity, with a few exceptions. Some relationships disappeared or weakened, such as acetic acid ethyl ester, which no longer showed a tendency to be positively related to $\mathrm{CH}_{4}$ intensity, and the significant positive relationship of ethyl butanoate, which became a tendency upon including FPCM as covariate. Another relationship strengthened; the tendency for a negative relationship of hexanal became significant upon including FPCM as covariate.

Nonvolatile Metabolites. In the present study, 41 nuclear magnetic resonances could be assigned either to a nonvolatile compound or to a member of a class of nonvolatile compounds. The relationships between each individual nonvolatile metabolite and $\mathrm{CH}_{4}$ production, $\mathrm{CH}_{4}$ yield, and $\mathrm{CH}_{4}$ intensity are shown in Supplemental Tables S8, S9, and S10, respectively (https://doi.org/10 $.3168 /$ jds.2017-13334). The nonvolatile metabolites acetylcarnitine and UDP-hexose D were negatively related, whereas 11 nonvolatile metabolites, including acetate, $3 \mathrm{~N}$-acetylsugars, and succinate, were positively related to $\mathrm{CH}_{4}$ production. Only one nonvolatile metabolite, UDP-hexose $\mathrm{C}$, was negatively related, and no single nonvolatile metabolite was positively related to $\mathrm{CH}_{4}$ yield. Similarly, with respect to $\mathrm{CH}_{4}$ intensity, only citrate was negatively related. In contrast, 14 nonvolatile metabolites, including acetate, methylmalonate, and succinate, were positively related to $\mathrm{CH}_{4}$ intensity. The relationships between each nonvolatile metabolite and $\mathrm{CH}_{4}$ intensity including FPCM as a covariate are shown in Supplemental Table S10 (https://doi.org/10.3168/ jds.2017-13334). Including FPCM as a covariate in the regression model resulted in several changes. Many nonvolatile metabolites remained significantly related to $\mathrm{CH}_{4}$ intensity, whereas the relationship between $\mathrm{CH}_{4}$ intensity and 5 nonvolatile metabolites (including citrate and ethanol) disappeared. Other relationships, however, appeared or strengthened, including acetylcarnitine and the $3 \mathrm{~N}$-acetylsugars $\mathrm{C}, \mathrm{D}$, and $\mathrm{E}$ that became significantly positively related upon including FPCM as covariate.

\section{Prediction Models for $\mathrm{CH}_{4}$ Emission}

Four sets of test variables were used to develop $\mathrm{CH}_{4}$ prediction models; (1) MFA alone, (2) volatile metabolites alone, (3) nonvolatile metabolites alone, and (4) all 3 types of metabolites combined. In total, 11 prediction models were obtained: 4 for $\mathrm{CH}_{4}$ production, 3 for $\mathrm{CH}_{4}$ yield (no model was obtained with nonvolatile metabolites only), and 4 for $\mathrm{CH}_{4}$ intensity (Table 2). The observed and residual (observed minus predicted) versus predicted $\mathrm{CH}_{4}$ production, $\mathrm{CH}_{4}$ yield, and $\mathrm{CH}_{4}$ intensity plots are shown in Figures 1, 2, and 3 , respectively. The evaluation results (i.e., adjusted $\mathrm{R}^{2}$, RMSEP, and CCC analysis) of the 11 obtained $\mathrm{CH}_{4}$ prediction models are shown in Table 3.

Milk Fatty Acids Alone. The RMSEP of the MFA-based $\mathrm{CH}_{4}$ prediction models was $34 \mathrm{~g}$ of $\mathrm{CH}_{4} / \mathrm{d}$, $2.0 \mathrm{~g}$ of $\mathrm{CH}_{4} / \mathrm{kg}$ of DMI, and $1.7 \mathrm{~g}$ of $\mathrm{CH}_{4} / \mathrm{kg}$ of FPCM, respectively. Additionally, the adjusted $\mathrm{R}^{2}$ and $\mathrm{CCC}$ of the MFA-based $\mathrm{CH}_{4}$ prediction models ranged from 0.38 to 0.75 , and from 0.44 to 0.75 , respectively, with the prediction model for $\mathrm{CH}_{4}$ yield performing the worst and the prediction model for $\mathrm{CH}_{4}$ intensity performing the best. This is also evident by the lower $r$ and $C_{b}$ values for the MFA-based prediction model for $\mathrm{CH}_{4}$ yield relative to the MFA-based prediction model for $\mathrm{CH}_{4}$ 
MILK METABOLOME AND METHANE EMISSION

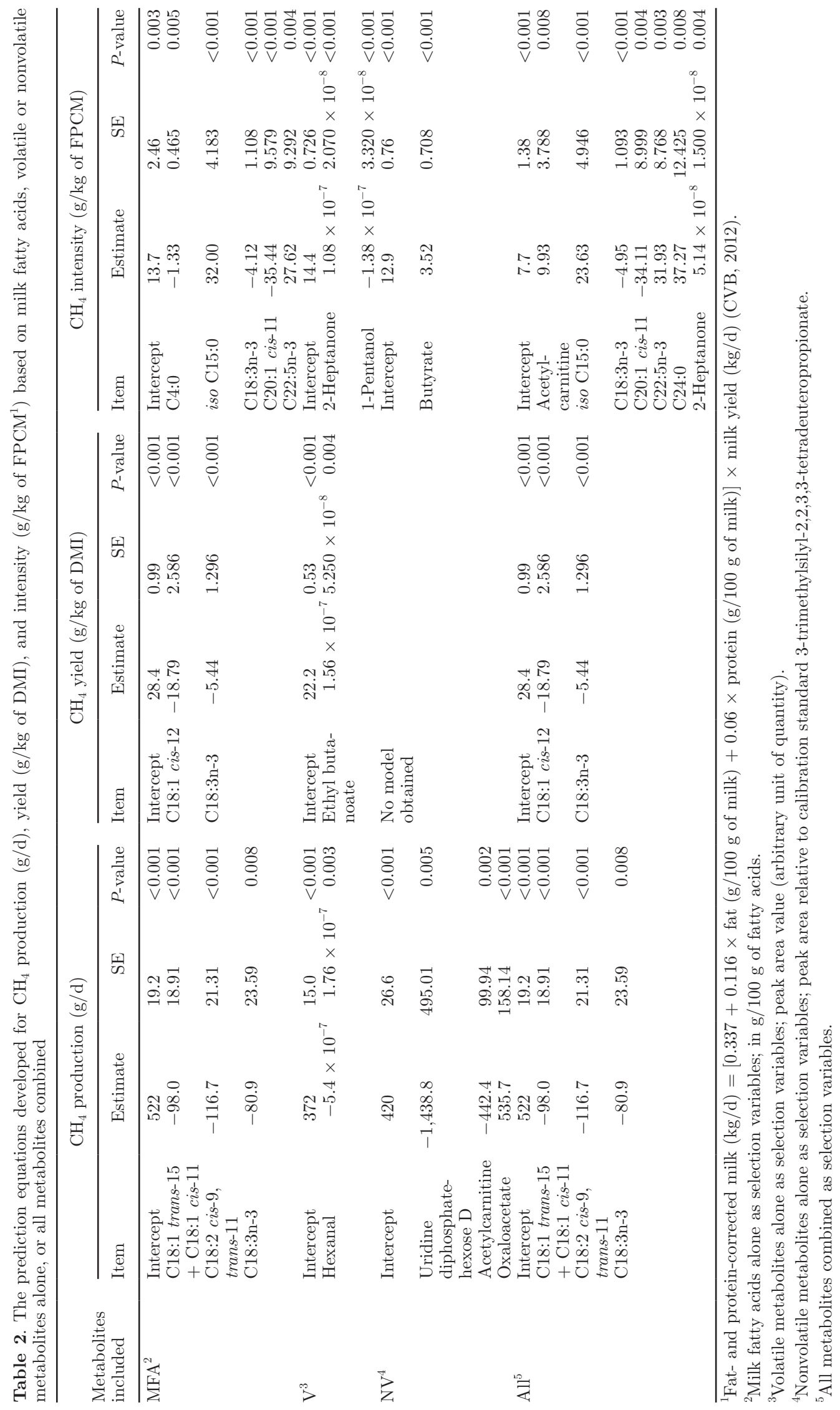



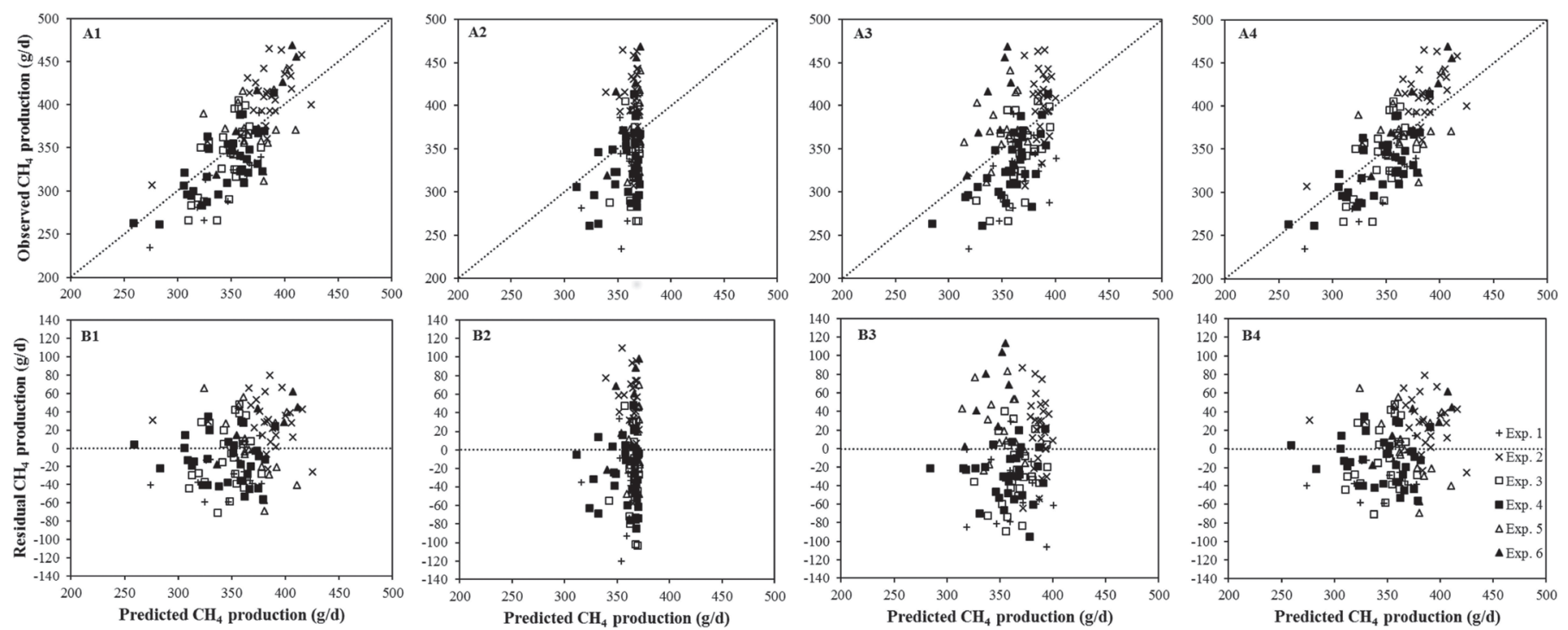

Figure 1. (A) Observed and predicted $\mathrm{CH}_{4}$ production (g/d), and (B) residual (i.e., observed - predicted) $\mathrm{CH}_{4}$ production (g/d), from the regression analyses based on milk fatty acids ( $\mathrm{g} / 100 \mathrm{~g}$ of fatty acids) alone (1), volatile metabolites alone (2), nonvolatile metabolites alone (3), and all metabolites combined (4). The slope of residuals regressed on predicted values did not differ significantly from zero. The different symbols identify the 6 individual experiments described in the Materials and Methods.

intensity. Although the MFA-based prediction models for $\mathrm{CH}_{4}$ production and $\mathrm{CH}_{4}$ intensity were equally precise (i.e., both having a $r$ value of 0.76 ), the MFA-based prediction model for $\mathrm{CH}_{4}$ intensity was more accurate $\left(C_{b}\right.$ of 0.99 for $\mathrm{CH}_{4}$ intensity and $C_{b}$ of 0.88 for $\mathrm{CH}_{4}$ production). The MFA-based prediction model for $\mathrm{CH}_{4}$ in-
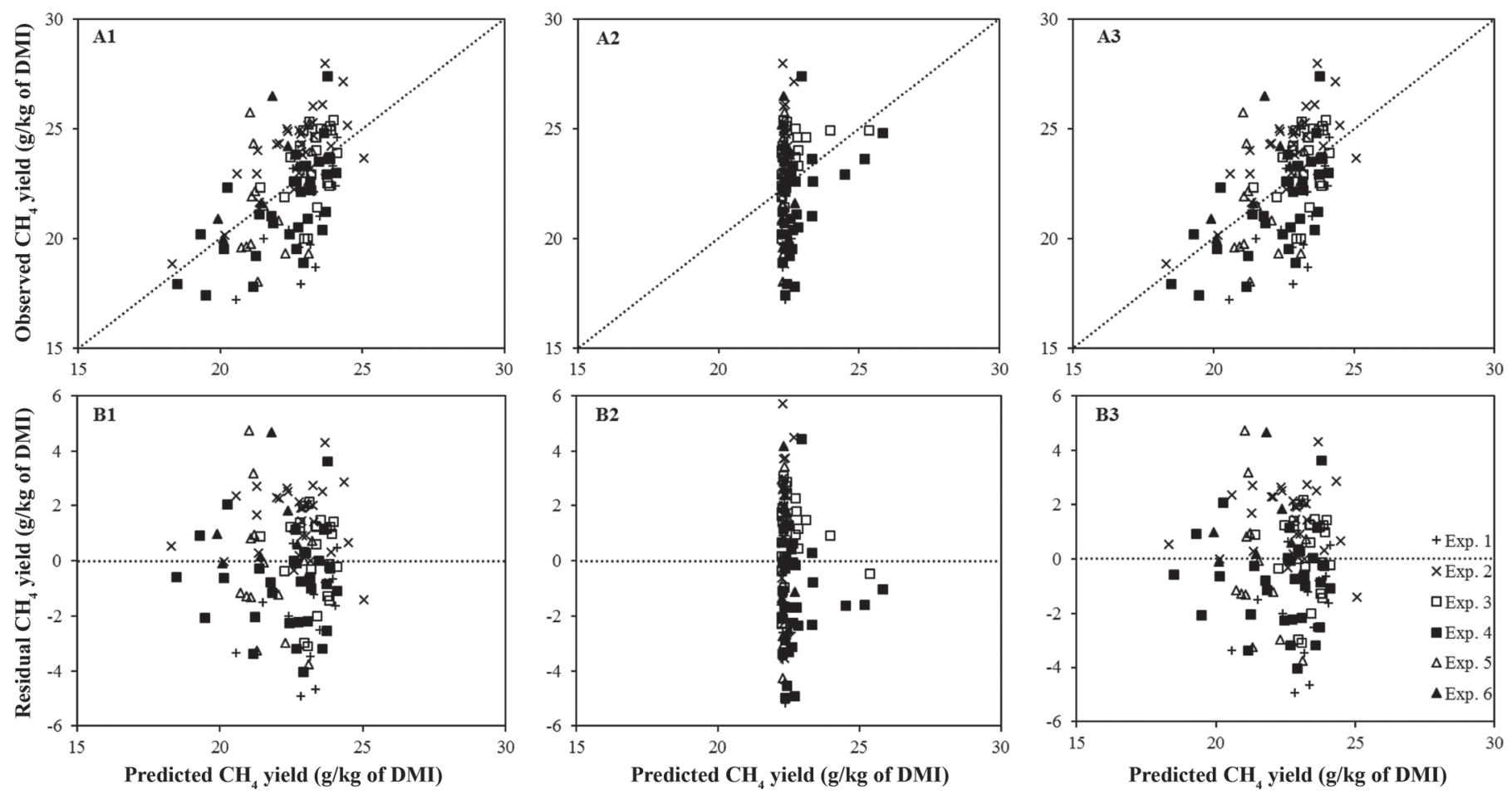

Figure 2. (A) Observed and predicted $\mathrm{CH}_{4}$ yield ( $\mathrm{g} / \mathrm{kg}$ of DMI), and (B) residual (i.e., observed - predicted) $\mathrm{CH}_{4}$ yield (g/kg of DMI), from the regression analyses based on milk fatty acids ( $\mathrm{g} / 100 \mathrm{~g}$ of fatty acids) alone (1), volatile metabolites alone (2), and all metabolites combined (3). The slope of residuals regressed on predicted values did not differ significantly from zero. The different symbols identify the 6 individual experiments described in the Materials and Methods. 

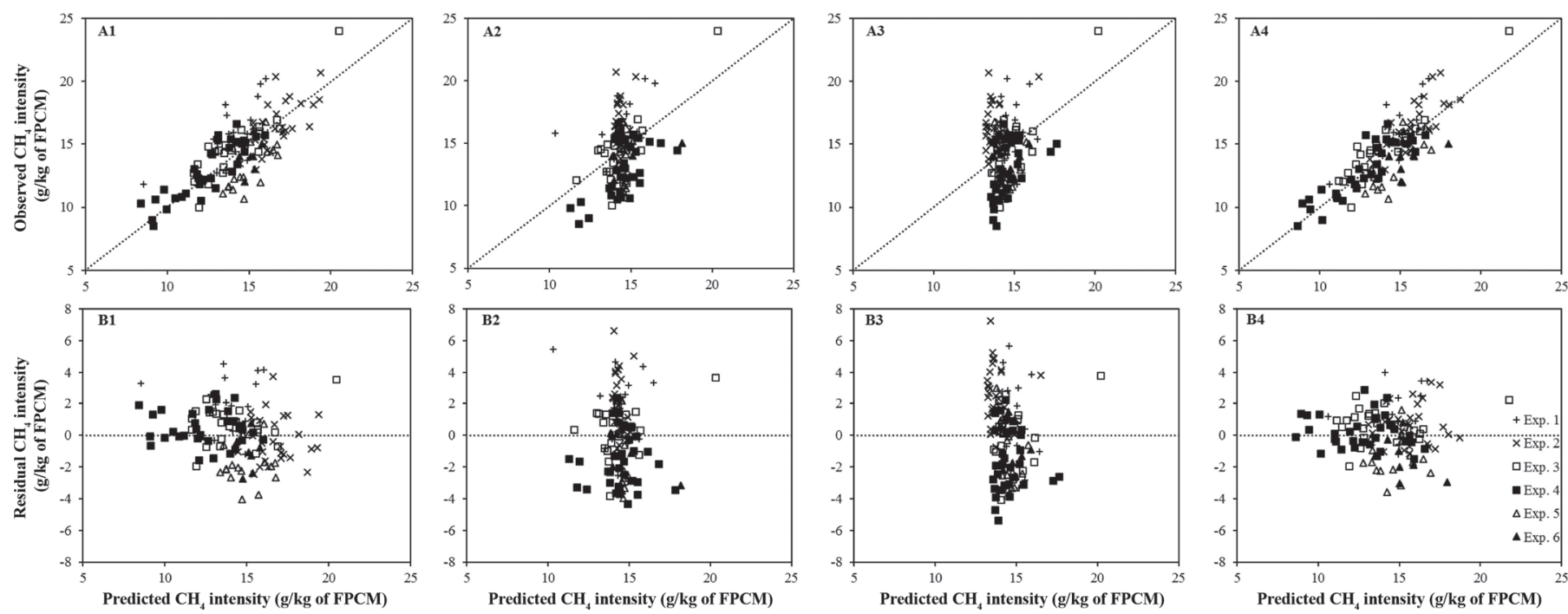

Figure 3. (A) Observed and predicted $\mathrm{CH}_{4}$ intensity $[\mathrm{g} / \mathrm{kg}$ of fat- and protein-corrected milk (FPCM)], and (B) residual (i.e., observed predicted) $\mathrm{CH}_{4}$ intensity ( $\mathrm{g} / \mathrm{kg}$ of $\mathrm{FPCM}$ ), from the regression analyses based on milk fatty acids ( $\mathrm{g} / 100 \mathrm{~g}$ of fatty acids) alone (1), volatile metabolites alone (2), nonvolatile metabolites alone (3), and all metabolites combined (4). The slope of residuals regressed on predicted values did not differ significantly from zero. The different symbols identify the 6 individual experiments described in the Materials and Methods.

tensity had the ability to describe more of the observed variation in $\mathrm{CH}_{4}$ emissions compared with MFA-based prediction models for $\mathrm{CH}_{4}$ production and $\mathrm{CH}_{4}$ yield. This is evident by the scale shift values, with the MFAbased prediction models for $\mathrm{CH}_{4}$ production and $\mathrm{CH}_{4}$ yield having a scale shift that was clearly higher than $1(v>1.67)$, whereas the scale shift of the MFA-based prediction for $\mathrm{CH}_{4}$ intensity was close to $1(v=1.14)$.

Volatile Metabolites Alone. The RMSEP of the volatile metabolite-based $\mathrm{CH}_{4}$ prediction models was $49 \mathrm{~g}$ of $\mathrm{CH}_{4} / \mathrm{d}, 2.3 \mathrm{~g}$ of $\mathrm{CH}_{4} / \mathrm{kg}$ of DMI, and $2.4 \mathrm{~g}$ of $\mathrm{CH}_{4} / \mathrm{kg}$ of FPCM. Additionally, the adjusted $\mathrm{R}^{2}$ and $\mathrm{CCC}$ of the volatile metabolite-based $\mathrm{CH}_{4}$ prediction models ranged from 0.07 to 0.27 , and from 0.07 to 0.29 , respectively, with the prediction model for $\mathrm{CH}_{4}$ yield performing the worst and the prediction model for $\mathrm{CH}_{4}$ intensity performing the best. The precision of these models (i.e., $r$ ) followed the same pattern, which was not the case for the accuracy of these models (i.e., $C_{b}$ ). The $C_{b}$ value was lowest for the volatile metabolitebased prediction model for $\mathrm{CH}_{4}$ production (0.42) and highest for the volatile metabolite-based prediction model for $\mathrm{CH}_{4}$ intensity (0.73). Further, all volatile metabolite-based $\mathrm{CH}_{4}$ prediction models had a scale shift that was clearly higher than $1(v>2.28)$, indicating the inability of volatile metabolites alone to predict the range of observed $\mathrm{CH}_{4}$ emissions.

Nonvolatile Metabolites Alone. No model was obtained for $\mathrm{CH}_{4}$ yield with nonvolatile metabolites alone. The significance level for a variable to enter the model was 0.01 , whereas the significance level of the strongest correlation between a nonvolatile metabolite (i.e., UDP-hexose $\mathrm{C}$ ) and $\mathrm{CH}_{4}$ yield was 0.035 . The RMSEP of the nonvolatile metabolite-based $\mathrm{CH}_{4}$ prediction models was $45 \mathrm{~g}$ of $\mathrm{CH}_{4} / \mathrm{d}$ and $2.6 \mathrm{~g}$ of $\mathrm{CH}_{4} / \mathrm{kg}$ of FPCM. Additionally, the adjusted $\mathrm{R}^{2}$ was 0.30 and 0.20 , and the CCC was 0.35 and 0.14 for the nonvolatile metabolite-based prediction models for $\mathrm{CH}_{4}$ production and $\mathrm{CH}_{4}$ intensity, respectively. Contrary to what was observed for MFA and volatile metabolites alone, the nonvolatile metabolite-based prediction model for $\mathrm{CH}_{4}$ production performed better than the nonvolatile metabolite-based prediction model for $\mathrm{CH}_{4}$ intensity. Both nonvolatile metabolite-based $\mathrm{CH}_{4}$ prediction models had a scale shift that was clearly higher than $1(v>$ $2.26)$, indicating the inability of nonvolatile metabolites alone to predict the range of observed $\mathrm{CH}_{4}$ emissions.

All Metabolites Combined. When combining the 3 types of milk metabolites, the RMSEP of the $\mathrm{CH}_{4}$ prediction models was $34 \mathrm{~g}$ of $\mathrm{CH}_{4} / \mathrm{d}, 2.0 \mathrm{~g}$ of $\mathrm{CH}_{4} / \mathrm{kg}$ of DMI, and $1.5 \mathrm{~g}$ of $\mathrm{CH}_{4} / \mathrm{kg}$ of FPCM. Additionally, the adjusted $\mathrm{R}^{2}$ and $\mathrm{CCC}$ of the $\mathrm{CH}_{4}$ prediction models including all 3 types of metabolites ranged from 0.38 to 0.74 , and from 0.44 to 0.80 , respectively, with the prediction model for $\mathrm{CH}_{4}$ yield performing the worst and the prediction model for $\mathrm{CH}_{4}$ intensity performing the best. A similar pattern was observed for the precision $(r)$, accuracy $\left(C_{b}\right)$, and the scale shift $(v)$ of the $\mathrm{CH}_{4}$ prediction models combining the 3 types of metabolites. The prediction models using the combination of all 3 types of milk metabolites performed better than the prediction models with volatile metabolites 
VAN GASTELEN ET AL.

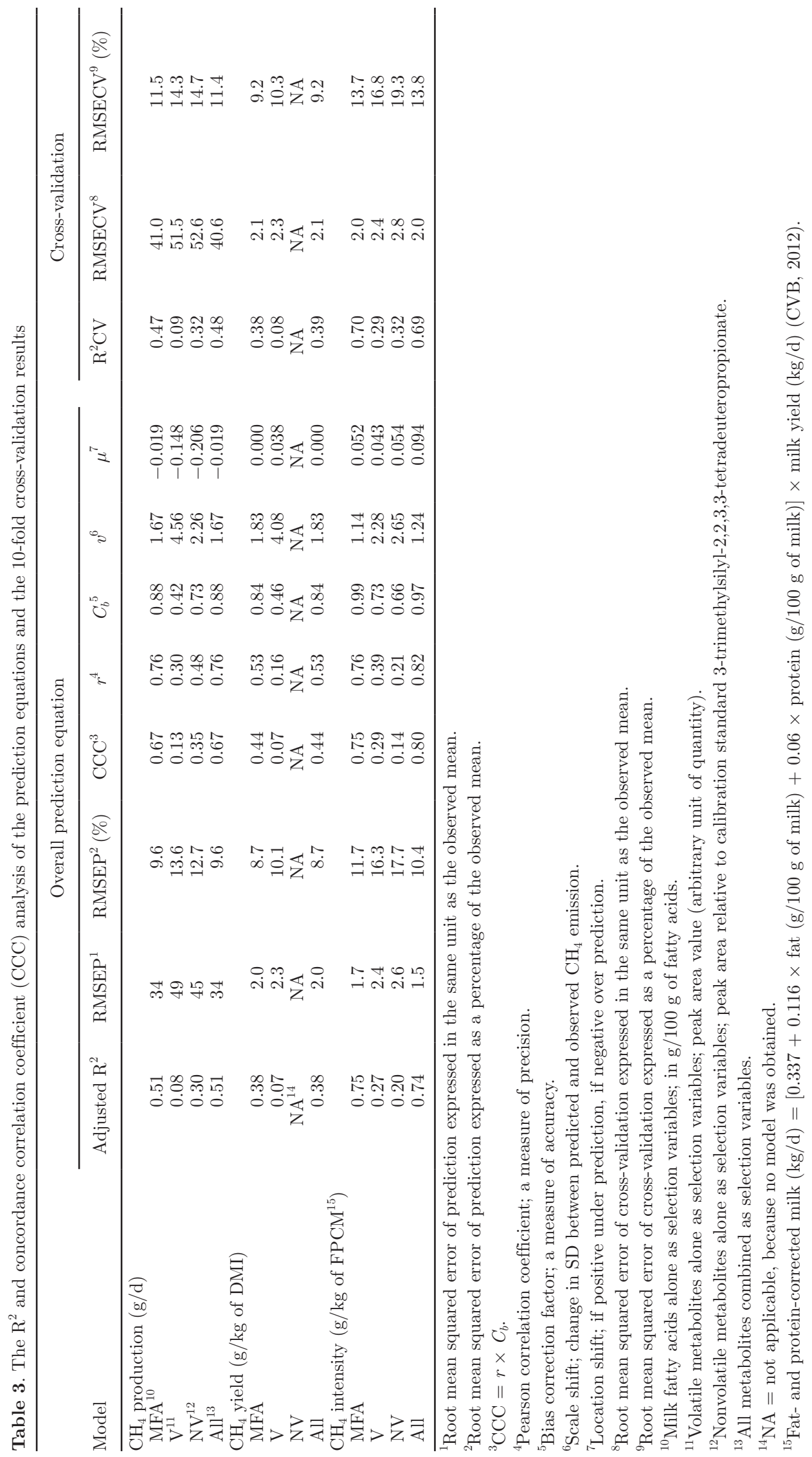


alone and nonvolatile metabolites alone. For both $\mathrm{CH}_{4}$ production and $\mathrm{CH}_{4}$ yield, only MFA were selected in the prediction models, resulting in $\mathrm{CH}_{4}$ prediction models identical to the MFA-based $\mathrm{CH}_{4}$ prediction models. For $\mathrm{CH}_{4}$ intensity, all 3 types of milk metabolites were selected in the prediction model: 5 MFA, 1 volatile metabolite, and 1 nonvolatile metabolite.

Cross-Validation. The results of the internal crossvalidation of all $\mathrm{CH}_{4}$ prediction models are also shown in Table 3. Additionally, Supplemental Table S11 (https://doi.org/10.3168/jds.2017-13334) shows the MFA, volatile metabolites, and nonvolatile metabolites that were included in the prediction models in the crossvalidation, and whether or not these milk metabolites were also part of the best overall prediction models (Table 2). The $\mathrm{R}^{2} \mathrm{CV}$ and the RMSECV (\%) of the MFA-based $\mathrm{CH}_{4}$ prediction models ranged from 0.38 to 0.70 and from 9.2 to 13.7 , respectively. Further, the $\mathrm{R}^{2} \mathrm{CV}$ and the RMSECV (\%) of the volatile metabolitebased $\mathrm{CH}_{4}$ prediction models ranged from 0.08 to 0.29 and from 10.3 to 16.8 , respectively. The $\mathrm{R}^{2} \mathrm{CV}$ was 0.32 and 0.32, and the RMSECV (\%) was 14.7 and 19.3 for the nonvolatile metabolite-based prediction models for $\mathrm{CH}_{4}$ production and $\mathrm{CH}_{4}$ intensity, respectively. For the $\mathrm{CH}_{4}$ prediction models combining all 3 types of milk metabolites, the $\mathrm{R}^{2} \mathrm{CV}$ and the RMSECV (\%) ranged from 0.39 to 0.69 and from 9.2 to 13.8 , respectively.

\section{DISCUSSION}

\section{Relationship Between Individual Milk Metabolites and $\mathrm{CH}_{4}$ Emission}

Milk Fatty Acids. Van Gastelen and Dijkstra (2016) reviewed studies that investigated the predictive power of MFA composition for $\mathrm{CH}_{4}$ emission. In line with this review, in the present study several SMCFA were positively related to $\mathrm{CH}_{4}$ emission. In general, these SMCFA remained related to $\mathrm{CH}_{4}$ intensity, or the relationship appeared or strengthened, upon including FPCM as covariate. These positive relationships are the result of the de novo synthesis of these MFA in the mammary gland mainly from acetate and butyrate produced in the rumen (Bauman and Griinari, 2003), which are both positively related to $\mathrm{CH}_{4}$ emission (Ellis et al., 2008). The main exception is $\mathrm{C} 4: 0$. The observed negative relationship between $\mathrm{C} 4: 0$ and $\mathrm{CH}_{4}$ emission in the present study was also observed by Dijkstra et al. (2011) and van Lingen et al. (2014). The significant negative relationship between $\mathrm{C} 4: 0$ and $\mathrm{CH}_{4}$ intensity disappeared $(P>0.10)$ upon including FPCM as covariate, which may indicate a dilution effect with $\mathrm{C} 4: 0$ increasing with decreasing FPCM.
The iso OBCFA were often positively related to $\mathrm{CH}_{4}$ emission in the present study and remained positively related to $\mathrm{CH}_{4}$ intensity upon including FPCM as covariate, which is in agreement with iso OBCFA being generally more abundant in fibrolytic bacteria (Vlaeminck et al., 2006). The anteiso OBCFA are generally more abundant in amylolytic bacteria and thus expected to be negatively relatively to $\mathrm{CH}_{4}$ emission (Vlaeminck et al., 2006). This was observed for anteiso $\mathrm{C} 17: 0$ and $\mathrm{CH}_{4}$ production, but anteiso C15:0 was positively related to $\mathrm{CH}_{4}$ intensity. The latter MFA remained positively related to $\mathrm{CH}_{4}$ intensity upon including FPCM as covariate. A high level of ruminal propionate is related to low $\mathrm{CH}_{4}$ production, and propionate is a substrate for de novo synthesis of $\mathrm{C} 15: 0$ and $\mathrm{C} 17: 0$. Hence, both C15:0 and $\mathrm{C} 17: 0$ are hypothesized to be negatively related to $\mathrm{CH}_{4}$ emissions (Vlaeminck and Fievez, 2005). In the present study, only C17:0 was negatively related to $\mathrm{CH}_{4}$ production, whereas $\mathrm{C} 15: 0$ was positively related to all units of $\mathrm{CH}_{4}$ emission and $\mathrm{C} 17: 0$ was positively related to $\mathrm{CH}_{4}$ yield. The reason behind these positive relationships is not completely clear to us, but they are in agreement with other studies, such as Chilliard et al. (2009), Dijkstra et al. (2011), and van Lingen et al. (2014), although inconsistent with the findings of Rico et al. (2016). Additionally, it is unclear why C15:0 and C17:0 are differently related to $\mathrm{CH}_{4}$ emission, despite their similar synthesis pathways.

The negative relationships found in the present study between C18:1, C18:2, and C18:3 isomers in milk and $\mathrm{CH}_{4}$ emissions are in general agreement with others (van Lingen et al., 2014; Rico et al., 2016), and can be explained by dietary UFA and their biohydrogenation products (van Gastelen and Dijkstra, 2016). The relationship between $\mathrm{CH}_{4}$ intensity and several C18:1 isomers as well as C18:2 cis-9, trans-11 strengthened or appeared after correcting for FPCM yield. This suggests that the relationship between these MFA and FPCM can hamper the direct relation between MFA and $\mathrm{CH}_{4}$ intensity. The relationships found in the present study between $\mathrm{CH}_{4}$ emissions and long-chain fatty acids, which derive from absorption from the digestive tract and body fat mobilization (Bauman and Griinari, 2003), have been reported before (i.e., Chilliard et al., 2009; Rico et al., 2016; van Gastelen et al., 2017). The individual relationships found in the present study between $\mathrm{CH}_{4}$ emission and the long-chain fatty acids with more than 20 carbons were generally unaffected when including FPCM as a covariate. Additionally, these long-chain fatty acids were also included in the $\mathrm{CH}_{4}$ prediction models. This together suggests that these MFA are important in terms of $\mathrm{CH}_{4}$ prediction.

Volatile Metabolites. In contrast to Antunes-Fernandes et al. (2016), in the present study, many volatile 
metabolites in milk were related to $\mathrm{CH}_{4}$ emission and the relationships found between the volatile metabolites and $\mathrm{CH}_{4}$ intensity were not only the result of the relationship between the volatile metabolites in milk and FPCM. The lack of relationships found by AntunesFernandes might be the result of the limited variation in dietary treatments used, which was the exchange of fiber-rich grass silage with starch-rich corn silage. As shown by Hettinga et al. (2008), the volatile composition of milk was affected by supplementing diets with specific byproducts (including onions and cabbage) but was not affected by variation in the starch to fiber content of the diet, even though the latter manipulation has an influence on ruminal fermentation and $\mathrm{CH}_{4}$ emission (Hassanat et al., 2013; van Gastelen et al., 2015). The present study involved a wide variety of dietary treatments, including different qualities of forage, which are known to effect the volatile composition of milk (Thomson et al., 2005), ruminal fermentation, and $\mathrm{CH}_{4}$ emission (Warner et al., 2016).

In the present study, acetone was negatively related to both $\mathrm{CH}_{4}$ production and $\mathrm{CH}_{4}$ intensity. Acetone is a ketone body that can be used to identify cows with negative energy balance and subclinical ketosis (Andersson and Emanuelson, 1985). Gravert et al. (1991) reported that the quality of grass or maize silage was negatively related to milk acetone, and it has been suggested that, in general, silage feeding or the content of butyric acid in silage may affect milk acetone (Andersson and Emanuelson, 1985; Andersson and Lundström, 1985). This suggests that milk acetone can be affected by the same dietary factors that can affect $\mathrm{CH}_{4}$ emissions, explaining the negative relationship found in the present study.

Kalač (2011) reported that the occurrence of both acids and alcohols in silage result in the formation of various ethyl esters. Limited information is available on the transfer efficiency of both acids and esters from silage to milk, but the dietary treatments could have affected the relationships found in the present study. However, esters can also be formed within the mammary gland, from esterification of short-chain alcohols and FFA (Toso et al., 2002), and they can indicate bacterial action (Hettinga et al., 2009). In the present study, both volatile esters (ethyl acetate and ethyl butanoate) tended to be or were positively related to $\mathrm{CH}_{4}$ intensity, but including FPCM as a covariate resulted in the disappearance or weakening of these relationships. This suggests that the positive relationships with $\mathrm{CH}_{4}$ intensity were due to a relationship between FPCM and both volatile esters.

In the present study, 1-pentanol was negatively related to $\mathrm{CH}_{4}$ production and $\mathrm{CH}_{4}$ intensity. According to Moio et al. (1993), primary alcohols are formed by reduction of their respective aldehyde. Consequently, 1-pentanol is formed by the reduction of pentanal, which was not identified in the present study. Based on Villeneuve et al. (2013), it seems likely that the content of 1-pentanol in milk reflects the content of its respective aldehyde, pentanal. Straight-chain aldehydes, such as pentanal and hexanal, can derive from lipid degradation (Moio et al., 1993). Dietary lipids are negatively associated with $\mathrm{CH}_{4}$ emissions (Grainger and Beauchemin, 2011), potentially explaining the negative relationships found between $\mathrm{CH}_{4}$ emission and both 1-pentanol and hexanal in the present study. Further, dimethyl sulfone was negatively related to $\mathrm{CH}_{4}$ intensity. In the rumen, dimethyl sulfide is derived from the catabolism of sulfur AA, particularly methionine (Taylor and Kiene, 1989). Dimethyl sulfide is subsequently oxidized to dimethyl sulfone, which can be transferred to milk (Villeneuve et al., 2013). This suggests that the relationship between $\mathrm{CH}_{4}$ intensity and dimethyl sulfone could be the result of the dietary protein content, although the effect of dietary protein content on $\mathrm{CH}_{4}$ emissions is variable in the literature (Ellis et al., 2009; Reynolds et al., 2010).

We also identified 4 volatile FFA in the present study, all positively related to $\mathrm{CH}_{4}$ yield and $\mathrm{CH}_{4}$ intensity, but not with $\mathrm{CH}_{4}$ production. The concentration of FFA in milk is generally low and can be the result of incomplete esterification in the mammary gland before lipid secretion (Marsili, 2003) or spontaneous lipolysis (Chazal et al., 1987). The latter study also reported higher FFA concentrations in milk from cows fully fed on good quality grass silage compared with cows fully fed on good quality hay. Additionally, Chazal and Chilliard (1986) observed that milk from cows fed poor quality grass silage had higher FFA levels than milk from cows supplemented with corn silage. Moreover, Thomson et al. (2005) reported that FFA concentrations in milk were highest in summer when the quality of the pasture declines. This together suggests that the positive relation between volatile FFA in milk and both $\mathrm{CH}_{4}$ yield and $\mathrm{CH}_{4}$ intensity might be the results of dietary composition and quality, which affect both the composition of volatile metabolites in milk and enteric $\mathrm{CH}_{4}$ production.

Nonvolatile Metabolites. Similar to Antunes-Fernandes et al. (2016), nonvolatile metabolites were generally better correlated with $\mathrm{CH}_{4}$ intensity than with $\mathrm{CH}_{4}$ yield. Antunes-Fernandes et al. (2016) reported that the positive relationship between $\mathrm{CH}_{4}$ intensity and the nonvolatile metabolites acetoacetate, creatinine, ethanol, formate, methylmalonate, and $N$-acetylsugar A were due to the relationship between these nonvolatile metabolites and FPCM. This was also observed for creatinine and ethanol in the present study, as well as for the metabolites betaine, citrate, $N$-acetylsugar B, 
and sugar A. This suggest that these metabolites have no clear relationships with the ruminal $\mathrm{CH}_{4}$ emission metabolism, but rather are related to changes in milk yield or metabolic processes involved in milk synthesis. In contrast to Antunes-Fernandes et al. (2016), the 3 nonvolatile metabolites acetoacetate, methylmalonate, and $\mathrm{N}$-acetylsugar A remained related to $\mathrm{CH}_{4}$ intensity upon including FPCM as a covariate. Acetoacetate is a ketone body and can be positively related to fiber-rich diets and subsequently ketogenic VFA (van Knegsel et al., 2007), explaining the positive relationship found between acetoacetate and $\mathrm{CH}_{4}$ intensity. The concentration of methylmalonate in milk has been associated with dietary composition (Bauman and Griinari, 2001). When high grain or low forage diets are fed, the ruminal production of vitamin $\mathrm{B}_{12}$ decreases, whereas the production of propionate increases. This results in the accumulation of methylmalonate in the liver and subsequently, by transport via the circulatory system, in elevated methylmalonate supply to the mammary gland and increased concentration in milk (Bauman and Griinari, 2001). High grain or low forage diets are also associated with decreased $\mathrm{CH}_{4}$ emissions, and hence a negative relationship between methylmalonate and $\mathrm{CH}_{4}$ emission would be expected. In the present study, however, methylmalonate was positively related to $\mathrm{CH}_{4}$ intensity. The latter may be explained by the absence of a negative relationship between ruminal propionate and $\mathrm{CH}_{4}$ emissions in some of the studies of which the data were used for the present analysis (e.g., van Gastelen et al., 2015; Hatew et al., 2016).

$\mathrm{N}$-Acetylsugars are intermediates of biological pathways that occur in cell cytosol (Lu et al., 2013). $N$-acetylsugars C, D, and E were significantly and positively related to $\mathrm{CH}_{4}$ intensity only when including FPCM as a covariate. The results of the present study suggest that $\mathrm{N}$-acetylsugars are related to the ruminal $\mathrm{CH}_{4}$ production pathway. According to Lu et al. (2013), a higher concentration of $\mathrm{N}$-acetylsugars could indicate leakage of cellular components to milk or higher permeability of the cell membrane in the epithelial cells in the mammary gland. Both can subsequently be associated with the differences in epithelial cell membrane stability. Tian et al. (2016) found lower concentrations of $\mathrm{N}$-acetylsugars in milk of cows experiencing heat stress, and Antunes-Fernandes et al. (2016) found some $\mathrm{N}$ acetylsugars tending to be negatively related to $\mathrm{CH}_{4}$ yield. However, it is unclear how differences in dietary composition could have changed the epithelial cell membrane stability in the mammary gland and how this relates to $\mathrm{CH}_{4}$ emissions, warranting more research.

Antunes-Fernandes et al. (2016) showed that citrate and UDP-hexose $\mathrm{B}$ were both negatively related to $\mathrm{CH}_{4}$ intensity, potentially reflecting decreased meta- bolic activity in the mammary gland with increased $\mathrm{CH}_{4}$ intensity as citrate is an intermediate of the Krebs cycle (Bremer and Davis, 1974) and UDP-hexose B is an intermediate of lactose metabolism (Cant et al., 2002). In the present study, citrate was also negatively related to $\mathrm{CH}_{4}$ intensity. However, this relationship disappeared upon inclusion of FPCM as a covariate. This suggests that changes in milk citrate may be related to the energy metabolism of the mammary gland, as previously suggested by Faulkner and Peaker (1982), which is not necessarily related to changes in $\mathrm{CH}_{4}$ intensity. Furthermore, UDP-hexose B was not related to $\mathrm{CH}_{4}$ intensity in the present study, which is in disagreement with Antunes-Fernandes et al. (2016). The other UDP-hexoses were negatively related to $\mathrm{CH}_{4}$ production (i.e., UDP-hexose D), $\mathrm{CH}_{4}$ yield (i.e., UDPhexose $\mathrm{C}$ ), and $\mathrm{CH}_{4}$ intensity (i.e., UDP-hexose $\mathrm{D}$ upon including FPCM as a covariate). The negative relationship with $\mathrm{CH}_{4}$ production is surprising, because UDPhexoses are intermediates of lactose synthesis (Cant et al., 2002), and milk yield is controlled by the synthesis of lactose. Increased milk yield is often associated with increased feed intake and it is consistently reported in literature that increased feed intake is positively associated with $\mathrm{CH}_{4}$ production (Hristov et al., 2013). Subsequently, a positive relation between UDP-hexoses and $\mathrm{CH}_{4}$ production would be expected. The negative relationship between UDP-hexoses and $\mathrm{CH}_{4}$ yield can probably be explained by increased feed intake and the related decreased ruminal retention time of starch, which may result in increased postruminal digestion and subsequently glucose absorption (Rius et al., 2010) and conversion to UDP-hexoses in the mammary gland.

Acetate was positively related to $\mathrm{CH}_{4}$ emission, and remained related to $\mathrm{CH}_{4}$ intensity upon including FPCM as a covariate. This is in agreement with ruminal acetate production being positively associated with $\mathrm{CH}_{4}$ emission (Ellis et al., 2008). Furthermore, Krause and Oetzel (2005) demonstrated that ruminal succinate is usually only found at very low levels in the rumen, but that the concentration increased during SARA. In general, diets with a high starch content and a low fiber content are associated with decreased ruminal $\mathrm{pH}$ and $\mathrm{CH}_{4}$ emission (Beauchemin et al., 2008). Hence, a negative relationship between ruminal succinate and $\mathrm{CH}_{4}$ emission would be expected. However, we found a positive relationship between succinate in milk and $\mathrm{CH}_{4}$ emission. This suggests that succinate in milk does probably not directly reflect ruminal succinate levels.

The decrease of acetylcarnitine in milk with increasing $\mathrm{CH}_{4}$ production and $\mathrm{CH}_{4}$ intensity (acetylcarnitine became negative related to $\mathrm{CH}_{4}$ intensity upon including FPCM as a covariate) is in agreement with the results of the SMCFA in milk. It has been shown that 
acetylcarnitine reflects the inhibition of de novo fatty acid synthesis from acetate in the mammary gland (Erfle et al., 1970). De novo fatty acid synthesis in the mammary gland is inhibited by specific trans UFA, which are formed during ruminal biohydrogenation of dietary UFA (Bauman and Griinari, 2003). Certain dietary strategies (including low-fiber diets and highconcentrate diets) alter the rumen environment, lowering the ruminal $\mathrm{pH}$ and subsequently increasing the trans UFA being formed from ruminal biohydrogenation. Both dietary UFA and lower ruminal $\mathrm{pH}$ are also associated with reduction in $\mathrm{CH}_{4}$ emission, explaining the negative relationship between acetylcarnitine and $\mathrm{CH}_{4}$ emission.

Hippurate was positively related to $\mathrm{CH}_{4}$ production and $\mathrm{CH}_{4}$ intensity in the present study. Boudonck et al. (2009) showed that the concentration of hippurate was lower in milk of cows receiving organic diets (mainly forage-based) than in milk of cows receiving conventional diets (mainly concentrate-based). This suggest that increased forage content in the diet, which is accompanied by increased dietary fiber, increases hippurate content in milk. This might explain the relationship found in the present study, because dietary forage content, as well as dietary fiber content, is positively associated with $\mathrm{CH}_{4}$ emission (Beauchemin et al., 2008).

Overall, these results indicate that, next to MFA, both volatile and nonvolatile metabolites in milk are often related to $\mathrm{CH}_{4}$ emissions. These relationships are most likely the result of changes in dietary composition that affect not only enteric $\mathrm{CH}_{4}$ production, but also the profile of volatile and nonvolatile metabolites in milk. This illustrates that these milk metabolites might provide useful information increasing our understanding of $\mathrm{CH}_{4}$ emission of dairy cows.

\section{Prediction Models for $\mathrm{CH}_{4}$ Emission}

Milk Fatty Acids. The prediction potential of MFA varies between studies. The adjusted $\mathrm{R}^{2}$ values for the MFA-based prediction models for both $\mathrm{CH}_{4}$ production and $\mathrm{CH}_{4}$ yield from the present study are lower than the ones reported by other studies (Chilliard et al., 2009; Dijkstra et al., 2011; Rico et al., 2016). In contrast, the adjusted $\mathrm{R}^{2}$ values for the MFA-based prediction models for $\mathrm{CH}_{4}$ intensity of the present study are higher than those reported in literature (i.e., van Lingen et al., 2014). The scale shift results of the present study indicate that MFA are able to describe more of the observed variation in $\mathrm{CH}_{4}$ intensity than of the observed variation in $\mathrm{CH}_{4}$ production and $\mathrm{CH}_{4}$ yield. It is known that MFA are related to ruminal $\mathrm{CH}_{4}$ production pathways (Ellis et al., 2008; Chilliard et al., 2009), but it appears that the MFA can predict $\mathrm{CH}_{4}$ intensity better than $\mathrm{CH}_{4}$ production and $\mathrm{CH}_{4}$ yield. According to Dehareng et al. (2012), this might be due to $\mathrm{CH}_{4}$ intensity taking milk yield into account, which is directly associated with enteric $\mathrm{CH}_{4}$ production by cows and reflected by the MFA profile because of possible dilution effects. The results of the present study indeed show that some of the MFA are related to $\mathrm{CH}_{4}$ intensity due to their relationship with FPCM (e.g., C4:0). However, this is not the case for all MFA that are important for the prediction of $\mathrm{CH}_{4}$ intensity (such as iso C15:0).

Volatile Metabolites. The $\mathrm{CH}_{4}$ prediction potential of volatile metabolites alone appears low and is considerably less promising compared with MFA. Although the prediction potential of the volatile metabolites for $\mathrm{CH}_{4}$ production in this study is higher than van Gastelen et al. (2017) in which no model could be obtained for $\mathrm{CH}_{4}$ production, the adjusted $\mathrm{R}^{2}$ and $\mathrm{CCC}$ values of the volatile metabolite-based prediction models for $\mathrm{CH}_{4}$ yield and $\mathrm{CH}_{4}$ intensity are lower than the ones reported by van Gastelen et al. (2017).

Similar to van Gastelen et al. (2017), the potential of volatile metabolites to predict $\mathrm{CH}_{4}$ intensity in the present study was greater than their potential to predict $\mathrm{CH}_{4}$ production and $\mathrm{CH}_{4}$ yield, which is evidenced by the higher adjusted $\mathrm{R}^{2}$ and $\mathrm{CCC}$ values and lower scale shift. However, even for $\mathrm{CH}_{4}$ intensity, the large scale shift $(>2.28)$ shows that the variation in predicted $\mathrm{CH}_{4}$ emissions was considerably smaller than that in observed $\mathrm{CH}_{4}$ emission. This is illustrated in Figures 1,2 , and 3 and indicates the inability of volatile metabolites alone to predict the range of observed $\mathrm{CH}_{4}$ emissions.

Based on 1 experiment with 4 dietary treatments, van Gastelen et al. (2017) concluded that volatile metabolites alone hold potential to predict $\mathrm{CH}_{4}$ intensity, which might be the result of the relationship between volatile metabolites in milk and FPCM yield (AntunesFernandes et al., 2016). This is not supported by the results of the present study. First, the prediction potential of volatile metabolites for $\mathrm{CH}_{4}$ intensity is low. Second, most volatile metabolites remained significantly related to $\mathrm{CH}_{4}$ intensity upon including FPCM as a covariate. We therefore propose that, with a wide range of foragebased diets and a variety of quantity and quality of grass, grass silage, and corn silage, volatile metabolites in milk hold little potential to predict $\mathrm{CH}_{4}$ emissions, despite the relationships found between individual volatile metabolites and $\mathrm{CH}_{4}$ emissions.

Nonvolatile Metabolites. The adjusted $\mathrm{R}^{2}$ and CCC values reported in this study for nonvolatile metabolite-based $\mathrm{CH}_{4}$ prediction models were considerably lower than those reported by van Gastelen et al. (2017). Our results suggest that nonvolatile metabolites 
in milk have low $\mathrm{CH}_{4}$ prediction potential. For $\mathrm{CH}_{4}$ yield no model could be derived at all, which was to be expected given the low number of relationships (i.e., significant and tendency) between individual nonvolatile metabolites and $\mathrm{CH}_{4}$ yield. The variation in the predicted $\mathrm{CH}_{4}$ emissions was considerably smaller than that in observed $\mathrm{CH}_{4}$ emissions, as evidenced by the large scale shift $(>2.26)$. This is visualized in Figures 1 and 3 , and suggests that nonvolatile metabolites lack the ability to predict the range of $\mathrm{CH}_{4}$ emissions observed.

Van Gastelen et al. (2017) concluded, based on 1 experiment with 4 dietary treatments, that nonvolatile metabolites hold potential to predict $\mathrm{CH}_{4}$ intensity, which could largely be explained by the relationship between the nonvolatile metabolites in milk and FPCM yield as observed by Antunes-Fernandes et al. (2016). This is not supported by the results of the present study. We therefore propose that, with a wide range of forage-based diets with a variety of quantity and quality of grass, grass silage, and corn silage, nonvolatile metabolites in milk hold little potential to predict $\mathrm{CH}_{4}$ emissions despite the significant relationships found between individual nonvolatile metabolites and $\mathrm{CH}_{4}$ emissions.

All Metabolites Combined. No single proxy accurately predicts $\mathrm{CH}_{4}$ emission, and combinations of 2 or more proxies are likely to be a better solution to predict $\mathrm{CH}_{4}$ emission (reviewed by Negussie et al., 2017). In comparison with MFA alone, combining the 3 types of milk metabolites did not improve the potential to predict $\mathrm{CH}_{4}$ production and $\mathrm{CH}_{4}$ yield. The prediction models were actually identical to the ones obtained when selecting MFA alone. Also in the 10-fold crossvalidation, volatile and nonvolatile metabolites were rarely included in the prediction models (Supplemental Table S11; https://doi.org/10.3168/jds.2017-13334). These results clearly show that combining MFA with both volatile and nonvolatile metabolites has no added value in terms of $\mathrm{CH}_{4}$ production and $\mathrm{CH}_{4}$ yield prediction potential relative to MFA alone.

Similarly, for $\mathrm{CH}_{4}$ intensity, combining MFA with volatile and nonvolatile metabolites hardly improved prediction potential. Five MFA were included in the $\mathrm{CH}_{4}$ intensity prediction model, of which 4 were identical to the MFA included in the MFA-based prediction model for $\mathrm{CH}_{4}$ intensity. Despite the inclusion of one volatile metabolite (2-heptanone) and one nonvolatile metabolite (acetylcarnitine) in the combined model, the adjusted $\mathrm{R}^{2}$ was marginally lower (0.74) than that of the MFA-based prediction model for $\mathrm{CH}_{4}$ intensity (0.75). The CCC value of the prediction model for $\mathrm{CH}_{4}$ intensity combining the 3 metabolites was slightly higher than the one reported for the MFA-based $\mathrm{CH}_{4}$ intensity prediction model ( 0.80 and 0.75 , respectively), which was mainly the result of increased precision $(r)$.

In terms of the 10-fold cross-validation, MFA alone and the combination of the 3 types of milk metabolites performed equally well, having similar $\mathrm{R}^{2} \mathrm{CV}$ and $\mathrm{RM}-$ SECV values. When considering the metabolites that were included in the prediction models of the 10-fold cross-validation (Supplemental Table S11; https:// doi.org/10.3168/jds.2017-13334), it appears that the $\mathrm{CH}_{4}$ prediction models combining the 3 types of milk metabolites are less robust than the MFA-based $\mathrm{CH}_{4}$ prediction models, especially for $\mathrm{CH}_{4}$ intensity. Variation in the metabolites that were included in the crossvalidation was smaller for the MFA alone model (12 metabolites) than for the 3 types of metabolites combined (22 metabolites). Moreover, the MFA included in the best overall MFA-based prediction model for $\mathrm{CH}_{4}$ intensity were included at least 2 times in the 10-fold cross-validation. Contrary, 2 of the metabolites in the best overall prediction model for $\mathrm{CH}_{4}$ intensity combining the 3 types of milk metabolites were included only once (i.e., acetylcarnitine) or not at all (i.e., C24:0) in the cross-validation. The cross-validation results motivated us to develop a second best overall prediction model for $\mathrm{CH}_{4}$ intensity, but without acetylcarnitine and $\mathrm{C} 24: 0$. This resulted in a $\mathrm{CH}_{4}$ intensity prediction model with an adjusted $\mathrm{R}^{2}$ of 0.72 , a RMSEP of $1.6 \mathrm{~g}$ of $\mathrm{CH}_{4} / \mathrm{kg}$ of FPCM, a CCC of 0.78 , and a scale shift of 1.23. This illustrates that the prediction potential for $\mathrm{CH}_{4}$ intensity hardly differed when excluding acetylcarnitine and C24:0, which suggests that the prediction model for $\mathrm{CH}_{4}$ intensity combining the 3 types of metabolites is not robust.

Overall, our results indicate that combining MFA with milk volatile metabolites and nonvolatile metabolites does not improve the $\mathrm{CH}_{4}$ prediction potential relative to MFA alone. This is in agreement with van Gastelen et al. (2017) for $\mathrm{CH}_{4}$ production and $\mathrm{CH}_{4}$ yield. However, van Gastelen et al. (2017) reported a considerable improvement in the prediction potential when combining MFA with volatile and nonvolatile metabolites. The difference between the present study and van Gastelen et al. (2017) for $\mathrm{CH}_{4}$ intensity might be explained by the differences in the data set used by both studies. Although both studies only involved forage-based diets, the present study involved more observations (123 vs. 29 , respectively) and a larger variation in dietary treatments, $\mathrm{CH}_{4}$ emissions, DMI, and FPCM.

Our analyses suggest that the relationship between $\mathrm{CH}_{4}$ emission and both volatile and nonvolatile metabolites is largely driven by dietary composition and rumen fermentation. When investigating this relationship within a single experiment, with a small range of dietary treatments, these individual relationships en- 
sure sufficient prediction potential, as evidenced by van Gastelen et al. (2017) for $\mathrm{CH}_{4}$ intensity. However, as illustrated in the present study, upon combining data of multiple experiments that represent a wide range of dietary treatments, the diet driven individual relationships between $\mathrm{CH}_{4}$ emission and both volatile and nonvolatile metabolites are still present, but the prediction potential decreases considerably. This suggests that the wider range of dietary treatments hampers the $\mathrm{CH}_{4}$ prediction potential of volatile and nonvolatile metabolites. In contrast to volatile and nonvolatile metabolites, MFA are more directly related to the ruminal $\mathrm{CH}_{4}$ pathways (rumen microbial origin) and retain their prediction potential despite a wider range of dietary treatments, suggesting that MFA profile represents a more robust indicator for $\mathrm{CH}_{4}$ emission of dairy cows.

It is important to note though, that this study was based upon 6 experiments with forage-based diets only (forage varied between 70 and $85 \mathrm{~g} / 100 \mathrm{~g}$ of diet DM). Hence, the diets represent only a relative narrow range of forage-to-concentrate ratios. Additionally, milk production of the cows did not exceed $35 \mathrm{~kg} / \mathrm{d}$, and all cows were restricted in their feed intake to ensure similar feed intake between treatments, thus avoiding confounding effects of DMI on $\mathrm{CH}_{4}$ production. The relationships between $\mathrm{CH}_{4}$ emission and the 3 types of milk metabolites might be different, when more experiments would be included, involving more individual observations, and with more variety in dietary composition, feed intake, and milk yield.

Potential limitations aside, based on the results of the present study, it can be concluded that MFA have the greatest potential to predict $\mathrm{CH}_{4}$ emission of dairy cows compared with milk volatile and nonvolatile metabolites. Negussie et al. (2017) assessed several existing potential proxies for $\mathrm{CH}_{4}$ emissions of dairy cows, including proxies related to (1) feed intake and feeding behavior, (2) rumen function, metabolites, and microbiome, (3) milk production and composition, (4) hindgut and feces, and (5) measurements at the level of the whole animal (e.g., BCS, BW, and lactation stage). The authors of that review indicated that the accuracy of MFA to estimate $\mathrm{CH}_{4}$ emission was moderate to high, which is considerably higher than that of rumen-related variables, major milk components such as fat, lactose, and protein, and most variables of the whole animal, but similarly accurate as BW, digestibility, and milk yield (Negussie et al., 2017). Only feed intake (both alone and in combination with dietary composition) and milk infrared spectroscopy scored higher in terms of accuracy to estimate $\mathrm{CH}_{4}$ emission (Negussie et al., 2017). Because it is still a major challenge to measure feed intake in practice and because the current number of studies relating milk infrared spectroscopy with $\mathrm{CH}_{4}$ emission is limited, MFA remain an interesting proxy for $\mathrm{CH}_{4}$ emission of dairy cows.

\section{CONCLUSIONS}

Changes in concentrations of individual milk metabolites (i.e., MFA, volatile metabolites, and nonvolatile metabolites) can be related to the ruminal $\mathrm{CH}_{4}$ production pathway. These relationships are largely diet-driven (i.e., diet composition, intake, and passage affect both ruminal $\mathrm{CH}_{4}$ production and the milk metabolites). Some of the relationships between individual milk metabolites and $\mathrm{CH}_{4}$ intensity, however, were partly dependent on milk production (FPCM). Furthermore, the $\mathrm{CH}_{4}$ prediction potential of both volatile metabolites alone and nonvolatile metabolites alone is low, independent of the unit of $\mathrm{CH}_{4}$ emission. The $\mathrm{CH}_{4}$ prediction potential of MFA alone depended greatly on the unit in which $\mathrm{CH}_{4}$ emission was expressed. The potential was lowest for $\mathrm{CH}_{4}$ yield, intermediate for $\mathrm{CH}_{4}$ production, and highest for $\mathrm{CH}_{4}$ intensity. This study also demonstrates that, relative to MFA alone, $\mathrm{CH}_{4}$ prediction potential does not increase when combining MFA with volatile and nonvolatile metabolites, in particular for $\mathrm{CH}_{4}$ production and $\mathrm{CH}_{4}$ yield. Volatile and nonvolatile metabolites in milk contain information that may increase our understanding of enteric $\mathrm{CH}_{4}$ production of dairy cows, but it is not worthwhile to determine the volatile and nonvolatile metabolites in milk to estimate $\mathrm{CH}_{4}$ emission of dairy cows. Milk fatty acids have moderate potential to predict $\mathrm{CH}_{4}$ emission of dairy cattle fed forage-based diets, and the models can aid in the effort to understand and mitigate $\mathrm{CH}_{4}$ emissions of dairy cows.

\section{ACKNOWLEDGMENTS}

The authors acknowledge the project "Low Emission Animal Feed," which received financial support of the Dutch Ministry of Economic Affairs (The Hague, the Netherlands), Product Board Animal Feed (Zoetermeer, the Netherlands), and the Dutch Dairy Board (Zoetermeer, the Netherlands). Furthermore, Sudeb Saha, Pussamon Vongtongsalee, and Junchao Chen (all students of Wageningen University \& Research, the Netherlands) are gratefully acknowledged for their assistance.

\section{REFERENCES}

Andersson, L., and U. Emanuelson. 1985. An epidemiological study of hyperketonemia in Swedish dairy cows: Determinants and the relation to fertility. Prev. Vet. Med. 3:449-462. 
Andersson, L., and K. Lundström. 1985. Effect of feeding silage with high butyric acid content on ketone body formation and milk yield in postparturient dairy cows. Zentralbl. Veterinarmed. A 32:15-23.

Antunes-Fernandes, E. C., S. van Gastelen, J. Dijkstra, K. A. Hettinga, and J. Vervoort. 2016. Milk metabolome relates enteric methane emission to milk synthesis and energy metabolism pathways. J. Dairy Sci. 99:6251-6262.

Bauman, D. E., and J. M. Griinari. 2001. Regulation and nutritional manipulation of milk fat: low-fat milk syndrome. Livest. Prod. Sci. 70:15-29.

Bauman, D. E., and J. M. Griinari. 2003. Nutritional regulation of milk fat synthesis. Annu. Rev. Nutr. 23:203-227.

Beauchemin, K. A., M. Kreuzer, F. O'Mara, and T. A. McAllister. 2008. Nutritional management for enteric methane abatement: A review. Aust. J. Exp. Agric. 48:21-27.

Boudonck, K. J., M. W. Mitchell, J. Wulff, and J. A. Ryals. 2009. Characterization of the biochemical variability of bovine milk using metabolomics. Metabolomics 5:375-386.

Bremer, J., and E. J. Davis. 1974. Citrate as a regulator of acetylCoA metabolism in liver mitochondria. Biochim. Biophys. Acta 370:564-572

Cant, J. P., D. R. Trout, F. Qiao, and N. G. Purdie. 2002. Milk synthetic response of the bovine mammary gland to an increase in the local concentration of arterial glucose. J. Dairy Sci. 85:494-503.

Castro-Montoya, J. M., N. Pieren, J. Veneman, B. De Baets, S. De Campeneere, and V. Fievez. 2017. Predictions of methane emission levels and categories based on milk fatty acid profiles from dairy cows. Animal 11:1153-1162.

Chazal, M.-P., and Y. Chilliard. 1986. Effect of stage of lactation, stage of pregnancy, milk yield and herd management on seasonal variation in spontaneous lipolysis in bovine milk. J. Dairy Res. 53:529-538.

Chazal, M.-P., Y. Chilliard, and J. B. Coulon. 1987. Effect of nature of forage on spontaneous lipolysis in milk from cows in late lactation. J. Dairy Res. 54:13-18.

Chilliard, Y., C. Martin, J. Rouel, and M. Doreau. 2009. Milk fatty acids in dairy cows fed whole crude linseed, extruded linseed, or linseed oil, and their relationship with methane output. J. Dairy Sci. 92:5199-5211.

CVB. 2012. Chemische samenstellingen en nutritionele waarden van voedermiddelen (in Dutch). CVB (Centraal Veevoederbureau), The Hague, the Netherlands.

Dehareng, F., C. Delfosse, E. Froidmont, H. Soyeurt, C. Martin, N. Gengler, A. Vanlierde, and P. Dardenne. 2012. Potential use of milk mid-infrared spectra to predict individual methane emission of dairy cows. Animal 6:1694-1701.

Dijkstra, J., S. van Gastelen, E. C. Antunes-Fernandes, D. Warner, B. Hatew, G. Klop, S. C. Podesta, H. J. van Lingen, K. A. Hettinga, and A. Bannink. 2016. Relationships between milk fatty acid profiles and enteric methane production in dairy cattle fed grass- or grass silage-based diets. Anim. Prod. Sci. 56:541-548.

Dijkstra, J., S. M. van Zijderveld, J. A. Apajalahti, A. Bannink, W. J. J. Gerrits, J. R. Newbold, H. B. Perdok, and H. Berends. 2011. Relationships between methane production and milk fatty acid profiles in dairy cattle. Anim. Feed Sci. Technol. 166-167:590-595.

Ellis, J. L., J. Dijkstra, E. Kebreab, A. Bannink, N. E. Odongo, B. W. McBride, and J. France. 2008. Aspects of rumen microbiology central to mechanistic modelling of methane production in cattle. J. Agric. Sci. 146:213-233.

Ellis, J. L., E. Kebreab, N. E. Odongo, K. Beauchemin, S. McGinn, J. D. Nkrumah, S. S. Moore, R. Christopherson, G. K. Murdoch, B. W. McBride, E. K. Okine, and J. France. 2009. Modelling methane production from beef cattle using linear and nonlinear approaches. J. Anim. Sci. 87:1334-1345.

Erfle, J. D., L. J. Fisher, and F. Sauer. 1970. Carnitine and acetylcarnitine in the milk of normal and ketotic cows. J. Dairy Sci. $53: 486-489$.

Faulkner, A., and M. Peaker. 1982. Reviews of the progress of dairy science: Secretion of citrate into milk. J. Dairy Res. 49:159-169.
Grainger, C., and K. A. Beauchemin. 2011. Can enteric methane emissions from ruminants be lowered without lowering their production? Anim. Feed Sci. Technol. 166-167:308-320.

Gravert, H. O., E. Jensen, H. Hafezian, K. Pabst, and H. SchulteCoerne. 1991. Umweltbedingte und genetische Einflüsse auf den Acetongehalt der Milch. Zuchtungskunde 63:42-50.

Hammond, K. J., L. A. Crompton, A. Bannink, J. Dijkstra, D. R. Yáñez-Ruiz, P. O'Kiely, E. Kebreab, M. A. Eugène, Z. Yu, K. J. Shingfield, A. Schwarm, A. N. Hristov, and C. K. Reynolds. 2016. Review of current in vivo measurements techniques for quantifying enteric methane emission from ruminants. Anim. Feed Sci. Technol. 219:13-30.

Hassanat, F., R. Gervais, C. Julien, D. I. Massé, A. Lettat, P. Y Chouinard, H. V. Petit, and C. Benchaar. 2013. Replacing alfalfa silage with corn silage in dairy cow diets: Effects on enteric methane production, ruminal fermentation, digestion, $\mathrm{N}$ balance, and milk production. J. Dairy Sci. 96:4553-4567.

Hatew, B., A. Bannink, H. van Laar, L. H. de Jonge, and J. Dijkstra. 2016. Increasing harvest maturity of whole-plant corn silage reduced methane emission of lactating dairy cows. J. Dairy Sci. 99:354-368.

Heetkamp, M. J. W., S. J. J. Alferink, T. Zandstra, P. Hendriks, H. van den Brand, and W. J. J. Gerrits. 2015. Design of climate respiration chambers, adjustable to the metabolic mass of subjects. Pages 35-56 in Indirect Calorimetry. Techniques, Computations and Applications. W. J. J. Gerrits and E. Labussière, ed. Wageningen Academic Publishers, Wageningen, the Netherlands.

Hettinga, K. A., H. J. F. van Valenberg, T. J. G. M. Lam, and A. C. M. van Hooijdonk. 2009. The origin of the volatile metabolites found in mastitis milk. Vet. Microbiol. 137:384-387.

Hettinga, K. A., H. J. F. van Valenberg, and A. C. M. van Hooijdonk. 2008. Quality control of raw cows' milk by headspace analysis. Int. Dairy J. 18:506-513.

Hristov, A. N., J. Oh, J. L. Firkins, J. Dijkstra, E. Kebreab, G. Waghorn, H. P. S. Makkar, A. T. Adesogan, W. Yang, C. Lee, P. J. Gerber, B. Henderson, and J. M. Tricarico. 2013. Special topics - Mitigation of methane and nitrous oxide emissions from animal operations: I. A review of enteric methane mitigation options. J. Anim. Sci. 91:5045-5069.

Kalač, P. 2011. The effects of silage feeding on some sensory and health attributes of cow's milk: A review. Food Chem. 125:307-317.

Klop, G., J. Dijkstra, K. Dieho, W. H. Hendriks, and A. Bannink. 2017. Enteric methane production in lactating dairy cows with continuous feeding of essential oils or rotational feeding of essential oils and lauric acid. J. Dairy Sci. 100:3563-3575.

Krause, K. M., and G. R. Oetzel. 2005. Inducing subacute ruminal acidosis in lactating dairy cows. J. Dairy Sci. 88:3633-3639.

Lin, L. I. K. 1989. A concordance correlation coefficient to evaluate reproducibility. Biometrics 45:255-268.

Lu, J., E. Antunes Fernandes, A. E. Paez Cano, J. Vinitwatanakhun, S. Boeren, T. van Hooijdonk, A. van Knegsel, J. Vervoort, and K. A. Hettinga. 2013. Changes in milk proteome and metabolome associated with dry period length, energy balance, and lactation stage in postparturient dairy cows. J. Proteome Res. 12:3288-3296.

Marsili, R. T. 2003. Flavours and off-flavours in dairy foods. Pages 1069-1081 in Encyclopedia of Dairy Science. H. Roginski, J. W. Fuquay, and P. F. Fox, ed. Academic Press, New York, NY.

Mohammed, R., S. M. McGinn, and K. A. Beauchemin. 2011. Prediction of enteric methane output from milk fatty acid concentrations and rumen fermentation parameters in dairy cows fed sunflower, flax, or canola seeds. J. Dairy Sci. 94:6057-6068.

Moio, L., J. Dekimpe, P. Etievant, and F. Addeo. 1993. Neutral volatile compounds in raw milks from different species. J. Dairy Res. 60:199-213.

Negussie, E., Y. de Haas, F. Dehareng, R. Dewhurst, J. Dijkstra, N. Gengler, D. P. Morgavi, H. Soyeurt, S. van Gastelen, T. Yan, and F. Biscarini. 2017. Invited review: Large-scale indirect measurements for enteric methane emissions in dairy cattle: A review of proxies and their potential for use in management and breeding decisions. J. Dairy Sci. 100:2433-2453. 
Reynolds, C. K., L. A. Crompton, J. A. N. Mills, D. J. Humphries, P. Kirton, A. E. Relling, T. H. Misselbrook, D. R. Chadwick, and D. I. Givens. 2010. Effects of diet protein level and forage source on energy and nitrogen balance and methane and nitrogen excretion in lactating dairy cows. Pages $463-464$ in Proc. 3rd EAAP International Symposium on Energy and Protein Metabolism and Nutrition. G. M. Crovetto, ed. Wageningen Academic Publishers, Parma, Italy.

Rico, D. E., P. Y. Chouinard, F. Hassanat, C. Benchaar, and R. Gervais. 2016. Prediction of enteric methane emissions from Holstein dairy cows fed various forage sources. Animal 10:203-211.

Rius, A. G., J. A. D. R. N. Appuhamy, J. Cyriac, D. Kirovski, O. Becvar, J. Escobar, M. L. McGilliard, B. J. Bequette, R. M. Akers, and M. D. Hanigan. 2010. Regulation of protein synthesis in mammary glands of lactating dairy cows by starch and amino acids. J. Dairy Sci. 93:3114-3127.

Rodriguez, J. D., A. Pérez, and J. A. Lozano. 2010. Sensitivity analysis of $\mathrm{k}$-fold cross validation in prediction error estimation. IEEE Trans. Pattern Anal. Mach. Intell. 32:569-575.

St-Pierre, N. R. 2001. Invited review: Integrating quantitative findings from multiple studies using mixed model methodology. J. Dairy Sci. 84:741-755.

Taylor, B. F., and R. P. Kiene. 1989. Microbial metabolism of dimethyl sulfide. Pages 202-221 in Biogenic Sulfur in the Environment. E. S. Saltzman and W. J. Cooper, ed. Am. Chem. Soc., Washington, DC.

Thomson, N. A., M. W. Woolford, P. J. A. Copeman, and M. A. Auldist. 2005. Milk harvesting equipment and cow factors influencing seasonal variation in the levels of free fatty acids in milk from Waikato dairy herds. N. Z. J. Agric. Res. 48:11-21.

Tian, H., N. Zheng, W. Wang, J. Cheng, S. Li, Y. Zhang, and J. Wang. 2016. Integrated metabolomics study of the milk of heat-stressed lactating dairy cows. Sci. Rep. 6:24208.

Toso, B., G. Procida, and B. Stefanon. 2002. Determination of volatile compounds in cows' milk using headspace GC-MS. J. Dairy Res. 69:569-577.

van Gastelen, S., E. C. Antunes-Fernandes, K. A. Hettinga, and J. Dijkstra. 2017. Relationships between methane emission of Holstein Friesian dairy cows and fatty acids, volatile metabolites and nonvolatile metabolites in milk. Animal 11:1539-1548.

van Gastelen, S., E. C. Antunes-Fernandes, K. A. Hettinga, G. Klop, S. J. J. Alferink, W. H. Hendriks, and J. Dijkstra. 2015. Enteric methane production, rumen volatile fatty acid concentrations, and milk fatty acid composition in lactating Holstein-Friesian cows fed grass silage- or corn silage-based diets. J. Dairy Sci. 98:1915-1927.

van Gastelen, S., and J. Dijkstra. 2016. Prediction of methane emission from lactating dairy cows using milk fatty acids and midinfrared spectroscopy. J. Sci. Food Agric. 96:3963-3968.

van Knegsel, A. T., H. van den Brand, E. A. Graat, J. Dijkstra, R. Jorritsma, E. Decuypere, S. Tamminga, and B. Kemp. 2007. Dietary energy source in dairy cows in early lactation: Metabolites and metabolic hormones. J. Dairy Sci. 90:1477-1485.

van Lingen, H. J., L. A. Crompton, W. H. Hendriks, C. K. Reynolds, and J. Dijkstra. 2014. Meta-analysis of relationships between enteric methane yield and milk fatty acid profile in dairy cattle. J. Dairy Sci. 97:7115-7132.

Vanrobays, M.-L., C. Bastin, J. Vandenplas, H. Hammami, H. Soyeurt, A. Vanlierde, F. Dehareng, E. Froidmont, and N. Gengler. 2016. Changes throughout lactation in phenotypic and genetic correlations between methane emissions and milk fatty acid contents predicted from milk mid-infrared spectra. J. Dairy Sci. 99:7247-7260.

Villeneuve, M.-P., Y. Lebeuf, R. Gervais, G. F. Tremblay, J. C. Vuillemard, J. Fortin, and P. Y. Chouinard. 2013. Milk volatile organic compounds and fatty acid profile in cows fed timothy as hay, pasture, or silage. J. Dairy Sci. 96:7181-7194.

Vlaeminck, B., and V. Fievez. 2005. Milk odd- and branched-chain fatty acids to predict ruminal methanogenesis in dairy cows. Comm. Appl. Biol. Sci. Ghent Univ. 70:43-47.

Vlaeminck, B., V. Fievez, A. R. J. Cabrita, A. J. M. Fonseca, and R. J. Dewhurst. 2006. Factors affecting odd- and branched-chain fatty acids in milk: A review. Anim. Feed Sci. Technol. 131:389-417.

Warner, D., A. Bannink, B. Hatew, H. van Laar, and J. Dijkstra. 2017. Effects of grass silage quality and level of feed intake on enteric methane production in lactating dairy cows. J. Anim. Sci. 95:3687-3700.

Warner, D., B. Hatew, S. C. Podesta, G. Klop, S. van Gastelen, H. van Laar, J. Dijkstra, and A. Bannink. 2016. Effects of nitrogen fertilisation rate and maturity of grass silage on methane emission by lactating dairy cows. Animal 10:34-43.

Warner, D., S. C. Podesta, B. Hatew, G. Klop, H. van Laar, A. Bannink, and J. Dijkstra. 2015. Effect of nitrogen fertilization rate and regrowth interval of grass herbage on methane emission of zerograzing lactating dairy cows. J. Dairy Sci. 98:3383-3393. 